\title{
Competitividad y especialización de la economía de Guanajuato: un acercamiento municipal, 1993-2003
}

\section{Competitiveness and specialization of the economy of Guanajuato: a municipal approach, 1993-2003}

\author{
Kurt Francisco Unger-Rubín*
}

\begin{abstract}
The analysis of the economic and competitive evolution of the State of Guanajuato reveals a selection of few specializations and few municipalities with competitive leadership. The diversified municipalities have a better dynamic and are safer from sudden oscillations because of the proper and natural defense from risks which are neutralized; conversely, the mono-manufacturers are greatly exposed to changes with the risk of municipal viability as they solely depend on a single activity. The other municipalities are safe in the moderate defense of businesses and services, first-need non-commodifiable activities. The public policy must be more congruent recognizing those instances of assigned advantages and other different where the market can manage itself. In order to favor the development of competitive clusters with revealed regional specializations, some cases would suggest looking for the integration of broader regions which may transcend the very state.
\end{abstract}

Keywords: regional competitiveness, municipal specialization.

\section{Resumen}

El análisis de la evolución económica y competitiva del estado de Guanajuato revela una selección de pocas ramas de especialización y pocos municipios con liderazgo competitivo. Los municipios diversificados tienen una mejor dinámica y están más a salvo de oscilaciones bruscas por la propia y natural defensa de riesgos que se neutralizan. En cambio, los monomanufactureros tienen gran exposición a los cambios con el riesgo de la viabilidad del municipio al depender sustancialmente sólo de una actividad. Los otros municipios se resguardan más en la defensa moderada de comercios y servicios, actividades no comerciables de primera necesidad. La política pública debe ser más congruente reconociendo aquellas instancias de ventajas asignadas y otras diferentes en que el mercado puede arreglarse por sí mismo. Para favorecer el desarrollo de clusters competitivos con especializaciones regionales reveladas, algunos casos sugerirían buscar la integración de regiones más amplias que trascienden al propio estado.

Palabras clave: competitividad regional, especialización municipal.

* Centro de Investigación y Docencia Económicas, México. Correo-e: kurt.unger@cide.edu. 


\section{Introducción ${ }^{1}$}

Este trabajo pretende avanzar en la identificación de las características de las regiones del estado de Guanajuato que permitan fundamentar las acciones de política regional viables para impulsar los recursos industriales y de servicios de cada región. El acercamiento técnico refiere a Guanajuato, pero evidentemente se podría aplicar en otros contextos con las debidas adecuaciones a cada caso. El punto de atención son los municipios, considerando la trayectoria productiva y competitiva de las principales actividades, sus recursos naturales y las potencialidades que podrían ofrecer las nuevas inversiones en el marco de la globalización industrial y comercial en marcha.

El trabajo de Unger y Saldaña (1999) muestra la conformación de regiones en México con distintos grados de industrialización, atendiendo a dos criterios: el peso o importancia económica que alcanza la industria, y los niveles de progreso tecnológico y la modernización industrial que se observan en distintas actividades y localidades del país. El resultado de dicho estudio fue comprobar que existen diferencias significativas en la industrialización y modernización de las economías en todos los ámbitos geográficos, lo que refleja la importancia dominante de algunas actividades y localidades en cada estado. Esto da pie a lo que ahora nos proponemos identificar para el estado de Guanajuato, que son los sectores y clusters regionales y municipales más importantes que deberían servir de base para el impulso al desarrollo centrado en los recursos de cada localidad.

Un punto de partida esencial para proyectar su dinámica es distinguir entre actividades y clusters o aglomeraciones de actividades relacionadas de dos tipos, unos son los que se desarrollan principalmente con el liderazgo de productos industriales regionalmente especializados y concentrados (en principio urgidos de competitividad para resistir presiones comerciables), distinguiéndolos de otro tipo de actividades, incluidos servicios y comercios, que tienden a desarrollarse cerca de cada mercado o conjunto de población; éstos últimos son muy parecidos a los no comerciables, que disfrutan de protección natural por la corta distancia que guardan entre la demanda y su oferta.

Asimismo es importante distinguir entre comerciables orientados a la exportación y otros cuya dinámica está más cerca de la demanda acotada a los mercados nacionales. No obstante el privilegio que le damos a las

${ }^{1}$ El presente trabajo se basa en el documento "La evolución de la economía de Guanajuato posterior al TLCAN (1993-2003). Competitividad de los sectores y vocaciones de especialización municipales", informe presentado al Instituto de Planeación Estatal de Guanajuato (Iplaneg) y al Sistema Estatal de Financiamiento al Desarrollo (Sefide), del Gobierno del Estado de Guanajuato, en febrero de 2009. 
condiciones de mercado de inicio, veremos que puede haber otras características técnicas y económicas complementarias para explicar la dinámica y la competitividad de las actividades (ramas) de cada municipio, atendiendo también y en particular a la gestación ocasional de clusters de actividades que alcanzan cierta integración.

El debate entre convergencia y divergencia regional motivado por el crecimiento desigual de las economías regionales ha resurgido en ańos recientes, donde la evolución comparativa entre regiones de un mismo estado o país, o regiones en la vecindad entre países, es uno de los terrenos más fértiles para el análisis (Alba 1999; Glasmeier, 2000; RodríguezPosé, 2000; Cermeño et al., 2009). En el ámbito mexicano también surge a propósito de otra intención muy diferente, que busca aplicar la perspectiva regional al estudio de la innovación como un sistema (Cimoli, 2000; Unger, 2010, cap. 3).

La identificación de los municipios como centros de competitividad, por sobre la idea de competitividades nacionales, ha motivado a definir los sistemas locales y regionales que surgen alrededor de los recursos y ventajas más abundantes de cada región. En ese intento, las regiones se pueden definir más ambiciosamente como clusters locales de empresas, instituciones educativas y gubernamentales, más las capacidades conexas de I\&D, entrenamiento, consultoría técnica, estandarización y similares (Porter, 1990; Enright, 1997). En el contexto mexicano hay algunos antecedentes destacados, como el de Abdel (2000) con su estudio sobre Aguascalientes, y también Estrada (2006) en referencia explícita a Guanajuato.

En este ejercicio, la importancia de la región se centra en los municipios como unidad de análisis para intentar identificar a los actores que dan por resultado las ventajas competitivas presentes o potenciales de una región. La Organización para la Cooperación y el Desarrollo Económico (OCDE, 2007) ha venido trabajando en una dirección similar al destacar las características técnico-industriales en los estudios sobre clusters y sistemas de innovación de países europeos y escandinavos, ilustrando los obstáculos a la integración de los clusters regionales. En cualquier caso, el desempeño observado en cada situación de cierto éxito no puede separarse de la base técnica-industrial o comercial heredada en cada región, alrededor de la cual se desarrollan las redes que integran el cluster regional (Rodríguez-Posé, 2000: 21). Este enfoque industrial-sectorial-regional es el que aquí se privilegia para Guanajuato. 


\section{Importancia y dinámica de los sectores económicos del estado de Guanajuato}

El propósito de este trabajo es analizar las características económicas de los municipios del estado de Guanajuato, considerando aspectos como la importancia del producto interno bruto (РІв), la productividad, el empleo y otros factores de la organización industrial y tecnológica, para situar el origen de la competitividad en los diversos sectores de manufactura, comercio, servicios, minería, construcción y actividades agroindustriales. El objetivo es apreciar el grado de congruencia entre las ventajas competitivas sectoriales reveladas con claridad, con las prioridades de política para impulsar las vocaciones regionales, llevando la estimación a niveles muy precisos de municipios asociados a sus principales actividades (ramas y subramas) económicas.

Partimos de subrayar las coincidencias y las diferencias más significativas entre las actividades de especialización en los diferentes municipios. Es obvio que no todos han alcanzado las mismas condiciones de desarrollo, y posiblemente tampoco tienen las mismas expectativas a futuro. No obstante, en principio destaca la estrecha relación entre el crecimiento del PIB y la importancia de las manufacturas, como tendencia común en los municipios de Guanajuato. Esta tendencia es similar a la del país, con pocas excepciones basadas en el turismo y otros servicios modernos en las zonas urbanas.

La hipótesis de entrada es que aunque las manufacturas siguen presentándose con los mayores rendimientos de especialización virtuosa en general, al parecer las ventajas reveladas se encuentran en muy diversas circunstancias que es necesario precisar. En otro sentido al argumento de industrialización virtuosa, también hay casos de actividades industriales con una dinámica más moderada que conviene tener en cuenta para considerar los mecanismos y políticas más adecuados para su reconstrucción. Muchos de estos casos se relacionan con industrias tradicionales que extendieron demasiado el privilegio al mercado interno, o bien de actividades cuya orientación maquiladora es incierta, por su propia naturaleza de evolución.

\subsection{Importancia en VA, UE y empleos de sectores agregados}

El conjunto de empresas revisadas en los Censos Económicos de 2003 del país supera los tres millones de establecimientos. Guanajuato participa con 150,000. A manera de comparación, otros estados tienen números muy diferentes, desde uno muy desmedido como el Estado de México $(365,000)$ a Tabasco $(44,000)$ y Coahuila $(66,000$ establecimientos), que 
hacen una referencia muy preliminar al tamaño y a la diversidad relativa de actividades en cada uno.

A pesar de la diferencia en números, la distribución de empresas por sectores económicos en cada estado tiende a asemejarse al patrón nacional. Los comercios siempre son más de la mitad del total en establecimientos, pero las manufacturas tienden a alcanzar mayor importancia productiva. Los servicios y la infraestructura siguen, en ese orden, con importancias más sujetas a variación.

Los cuatro grandes sectores a revisar en Guanajuato representan un total de 203 actividades, entre las cuales destacan muy notablemente una decena por sobre las demás. ${ }^{2}$ La estimación de importancia más detallada en lo sucesivo se centra en 32 actividades, que dan cuenta de tres cuartas partes del PIB (VA) estatal de Guanajuato (cuadro 1). Estas mismas representan también un total de 83,500 empresas (unidades económicas: UE) y alrededor de 465,000 empleos en el estado (63.5\% del empleo total del año 2003, sin incluir al sector agropecuario).

La composición sectorial muestra una disparidad evidente entre manufacturas y los otros sectores: las manufacturas dan cuenta de la más alta participación en el va $(51.9 \%)$ con pocas empresas (menos de 18,000) y sólo $30.5 \%$ del personal ocupado. Las otras actividades importantes en los servicios y el comercio son de mucho menor productividad promedio por empleado, que se desarrollan en empresas de tamaño más moderado en términos de empleo. Los comercios suman 85,000 establecimientos y emplean a 270,000 , una media cercana a tres personas por establecimiento.

Las participaciones relativas de los cuatro sectores limitando a las actividades principales guardan representatividad muy similar a la estructura de participación en los totales: las manufacturas mantienen su importancia va y comparten la importancia en número de empresas y empleo con comercios y servicios. En esencia, quedan fuera muchas actividades (171) que se caracterizan por la presencia de numerosas empresas pequeńas y de baja productividad, sobre todo de comercio y servicios, cuyo crecimiento del empleo durante la década es moderado pero constante (45 por ciento).

\subsection{Dinámica 1993-2003: dos lustros muy dispares}

Las estimaciones de crecimiento por sectores se hacen a partir de trabajar en las equivalencias entre las clasificaciones censales de 2003, 1998 y 1993.

\footnotetext{
${ }^{2}$ La primera aclaración de suma importancia es la ausencia de referencia al sector agropecuario porque este sector no se incluye en las cifras de Censos Económicos, que son nuestra base de información. Las actividades corresponden a una o varias ramas definidas en cuatro dígitos, como se puede ver en el Anexo I. Las actividades importantes que aportan al menos $1 \%$ al PIB estatal son apenas 32 del total, sobre las cuales abunda el análisis al detalle.
} 


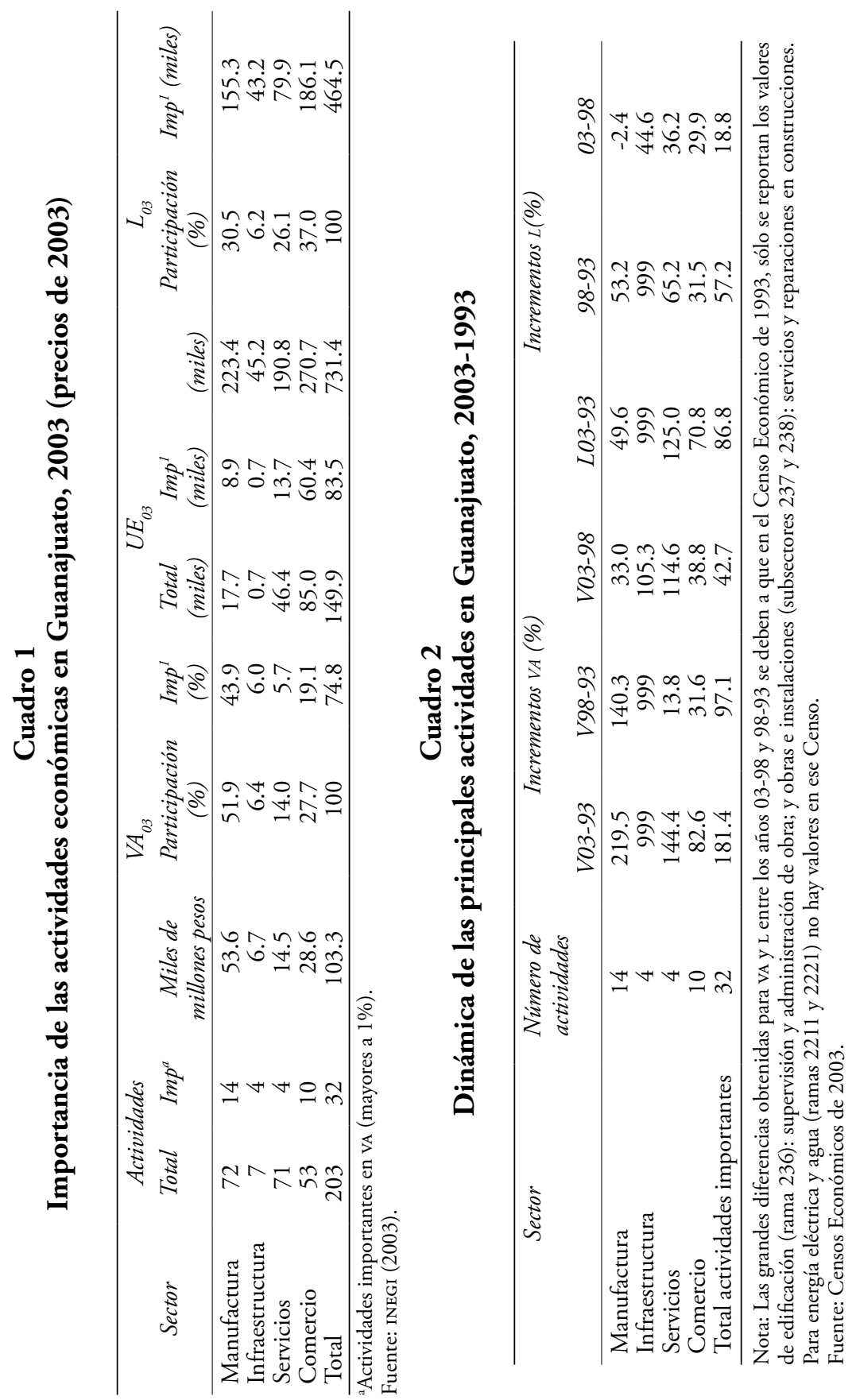


La equivalencia entre los dos ańos más recientes es cercana, pero para el año 1993 las asumimos por la descripción de cada rama, tomando las clases censales que las integran.

Contrario a la expectativa de efectos anticipados en la forma de cierres y desplazamientos de empresas por la puesta en vigor del Tratado de Libre Comercio de América del Norte (TLCAN), el crecimiento del primer lustro (1993-1998) para las actividades principales resultó considerablemente más exitoso que el segundo periodo, 1998-2003 (cuadro 2). El incremento porcentual de la producción (va) es más del doble en el primer lustro (97.1 y 42.7\%, respectivamente) y la creación de empleos también fue mucho mayor en el primer periodo. Tal vez es más concluyente decir que entre los años 1998-2003 se crearon pocos empleos (18.8\% de crecimiento) y las manufacturas en particular tuvieron contracción de empleos $(-2.4 \%)$ en ese periodo. Estas últimas experimentaron desfasadamente el efecto de reestructuraciones por el TLCAN, aunque tal vez recibieron otras influencias simultáneas no del todo entendidas todavía. ${ }^{3}$ En ese sector casi la mitad de las actividades redujo empleos, y por muy distintas causas, como veremos en la sección siguiente.

En comparación, el crecimiento de empleos en las actividades principales de servicios y comercios ha sido más exitoso (de 125 y $70 \%$ de incremento en la década después de 1993). Las manufacturas, por su parte, crecen a menor ritmo como resultado de la disparidad entre unas actividades muy dinámicas y otras en franca contracción, las cuales motivan nuestro análisis más detallado. También es evidente que el sector terciario se desarrolla con trayectorias dispares y en una dualidad de actividades, incluidas algunas poco formales, que dan por resultado un sector de características muy distantes a las que predominan en sectores de servicios modernos de las economías basadas en el conocimiento.

\section{Organización industrial, supervivencia de empresas y creación de empleos}

\subsection{Competencia, las empresas y empleos: tendencias sectoriales 1993-2003}

La teoría de la organización industrial intenta explicar los procesos de crecimiento mediante la distinción entre los sectores y las condiciones de competencia y competitividad particulares en cada situación geográfica

\footnotetext{
${ }^{3}$ Es inevitable reflexionar ante dichas experiencias. Por ejemplo, hoy es muy intrigante relacionar situaciones de crisis global que ya estaban en gestación (digamos que General Motors ahora es un símbolo inequívoco de crisis) y la tardía expresión de sus indicios críticos en una localidad de reciente arraigo, como Silao.
} 
y temporal. La literatura más sugerente que integra estructuras de competencia en entornos específicos de geografía, puede incluir una variedad de autores (Krugman, 1996; Porter, 1990; Shepherd, 1999).

En México, como en muchos otros países, generalmente las manufacturas son el sector más importante en la producción, y también es el sector que mejor ilustra la variedad de condiciones que pueden ocurrir en la organización industrial de las distintas actividades, en particular por las formas en que se desarrollan los mercados de productos industriales con modalidades muy diferentes. Algunas actividades manufactureras importantes se mantienen en el dominio de pocas empresas en mercados controlados por oligopolios nacionales e internacionales, otras pertenecen a mercados más competidos, donde el tamaño de las firmas dominantes no es tan determinante (Unger, 2005). Esas condiciones de competencia también imponen presiones muy distintas a la localización de las empresas, al acceso y a la adquisición de tecnologías y al imperativo de búsqueda o no del desarrollo de innovaciones o soluciones de competitividad que deben partir de las condiciones propias de cada circunstancia.

El sector agropecuario también mantiene algunas actividades promisorias, y en algunas partes es el que predomina, pero en general ha ido cediendo ante la dinámica manufacturera. ${ }^{4}$ Como veremos, hay algunos casos en que las cadenas o clusters industriales locales incorporan algunas actividades agropecuarias tradicionales en su dinámica y pueden llegar a convertirse, desde luego, en objetivo central y prioritario de la política industrial y de desarrollo local. La ilustración obvia es el cluster amplio de cuero-calzado en Guanajuato, que se encadena desde el origen al desarrollo de la ganadería. ${ }^{5}$ Otra actividad importante y también relacionada con el cluster agropecuario que despega recientemente son los productos lácteos, de natural extensión al ganado también y con derramas muy significativas en los alimentos balanceados, ${ }^{6}$ y productos congelados y envasados. La anticipación de clusters con base en recursos agropecuarios es por demás natural a la tradición económica de Guanajuato.

Los sectores de comercio y servicios presentan una panorámica muy diferente. En la primera impresión experimentan una competencia más intensa entre miles de empresas, pero ello sólo es aparente dado que en la realidad proliferan las actividades no transables (esto es, las que se desarrollan sin tener que enfrentar competidores externos a la localidad).

${ }^{4}$ Nuevamente debemos advertir y lamentar la ausencia de cifras censales en referencia al sector agropecuario.

${ }^{5}$ Se puede intentar la definición de cluster en su forma más ambiciosa como agrupamientos regionales integrados que aglutinan empresas, instituciones educativas y gubernamentales, más las capacidades conexas de I\&D, entrenamiento, consultoría técnica, estandarización y similares (OCDE, 1998).

${ }^{6}$ Los alimentos para animales han tenido una evolución bastante errática en Guanajuato, difícil de explicar, como se intentó mostrar en la versión más extensa de este trabajo (Unger, 2009). 


\section{Gráfica I \\ va de las principales actividades en Guanajuato, 2003 (porcentajes)}

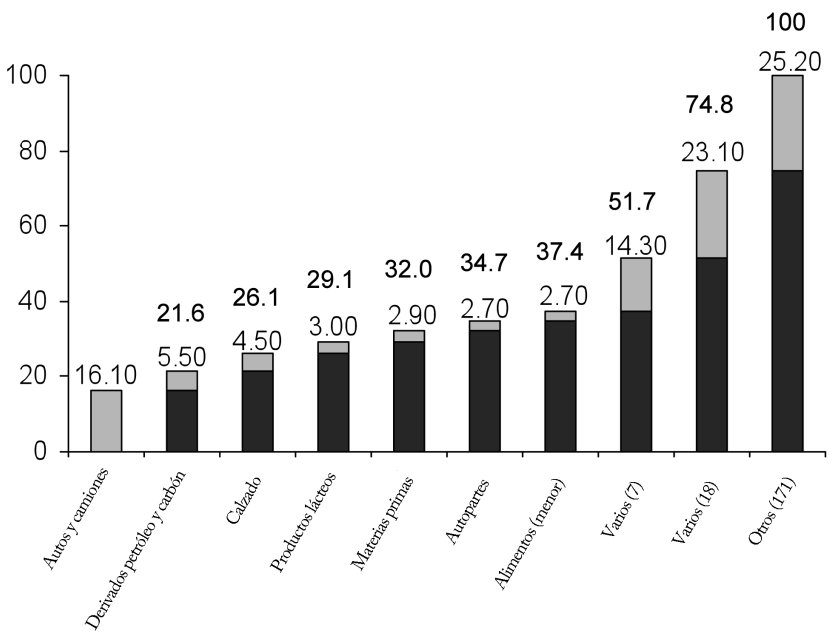

Varios (7): Ver actividades con participación entre 2.6\%-1.9\% de va03 en el Anexo I. Varios (18): Ver actividades con participación entre 1.8\%-1\% de va03 en el Anexo I. Otros (171): Ver actividades con participación menor a $1 \%$ de va03 en el Anexo I.

Fuente: Censos Económicos de 2003.

En el comercio y servicios lo local es la extensión territorial en que se definen los entornos de competencia real. Esos sectores crecen sin problemas por demandas derivadas de la dinámica económica y demográfica de cada localidad y compensan las caídas en los empleos agregados, también apuntalados en muchos casos por la expansión de la construcción. La contribución de estas actividades debe considerarse sin suponer que mejorarán por estar expuestas al mercado.

Las tendencias sectoriales esbozadas toman valores muy reveladores en la creación o cierre de empresas en la década posterior al TLCAN. Los cierres (cambio negativo en UE) son comunes en las actividades de manufacturas y mucho menores en los sectores terciarios. También los empleos en manufacturas se ven más expuestos a desplazamientos por falta de competitividad. Veamos las tendencias particulares de las actividades de importancia.

\subsection{La producción importante en Guanajuato: nuevas y viejas actividades}

La importancia de las actividades en producción es muy desigual. Retomando una primera indicación de la concentración en las 32 actividades 


\section{Gráfica II \\ Evolución del va de las principales actividades, 2003-1993 (millones de pesos de 2003)}

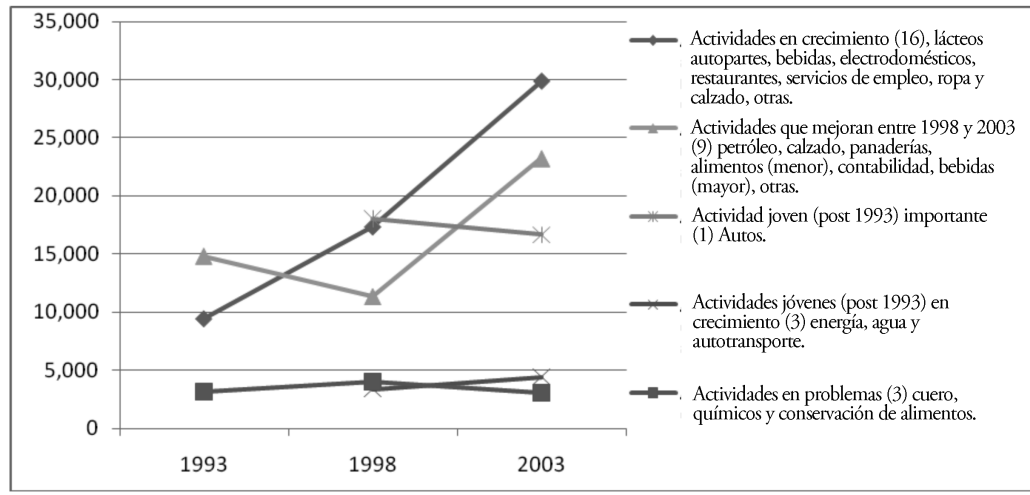

Fuente: Cuadro 3.

principales con participación en la producción superior a 1\%, la importancia en la cima es aún más desproporcionada: las primeras cuatro actividades (autos, petróleo, calzado y lácteos) aportan casi 30\%, la suma de las 14 primeras rebasa el 50\% (gráfica I). Entre las actividades predominan las de manufacturas (8), comercio (5) y servicios con restaurantes y hoteles.

Ahora bien, la dinámica durante 1993-2003 es variada entre estas actividades. Las hay con empresas de muy reciente instalación que en 1993 todavía no figuraban, o bien que crecieron aceleradamente después de 1998, de manera que en 2003 despegan hasta lo más alto. Es el caso de autos, autopartes, hierro y acero, electrodomésticos, lácteos, bebidas, construcción, energía eléctrica y autotransportes. En casi todas se trata de plantas muy específicas en localidades muy precisas también, como veremos más adelante. Otra situación corresponde a otras industrias que eran las líderes a principios de los años noventa y que en años recientes se han rezagado considerablemente: calzado, cuero, productos químicos y conservación de alimentos. La gráfica II de la evolución de las actividades principales es muy ilustrativa de la variedad de situaciones al respecto. ${ }^{7}$

Otras ramas más se comportan un tanto erráticas, con alzas y bajas pronunciadas de difícil explicación; entre las manufacturas, es el caso de derivados de petróleo y panadería. ${ }^{8}$ En otros sectores también hay

${ }^{7}$ Otras ramas de menor importancia y similar comportamiento incluyen carnes y alimentos para animales (Unger, 2009).

${ }^{8}$ La panadería industrial (Bimbo en Irapuato) reporta valor agregado muy bajo en el año 1998, sin cambiar significativamente el total de empleos, por lo que podría tratarse de un error en el levantamiento censal. Entre las actividades de menor importancia, el rubro de jabones y limpiadores en el municipio de San José Iturbide, que representa a la empresa Colgate Palmolive, también arroja cifras muy inconsistentes en cuanto a que el va que reportan es menor al total de sueldos y salarios 
variedad de tendencias. En servicios, el empleo en hoteles y restaurantes y despachos de contabilidad crecen con particular éxito durante el segundo lustro. Entre los comercios, también se mueven muy irregularmente las tendencias de minoristas de alimentos, mayoristas de bebidas y vehículos y refacciones (cuadro 3).

La contraparte explicativa de esas tendencias en la producción y las implicaciones de competitividad, puede estar en la dinámica de empleos y en algunas compactaciones de ramas que experimentan cierres de empresas, presumiblemente las menos competitivas. En cierto grado, sería extraño que estos cierres se dieran tardíamente, digamos entre 1998 y 2003, y en este sentido se distinguiría la reducción del número de empresas en casi todas las ramas de manufacturas: calzado, autopartes, electrodomésticos, cuero, prendas de vestir, conservación de alimentos, así como comercios de materias primas, bebidas y alimentos al mayoreo y autotransporte de carga.

\section{Ventajas reveladas y competitividad de las actividades principales}

\subsection{La competitividad de las actividades: tendencias estilizadas}

Hay diversas maneras de acercarse al tema de la competitividad en una localidad. La versión de características más económicas que adoptamos en este trabajo se basa en el índice de las ventajas comparativas reveladas del comercio (originalmente desarrollado por Balassa, 1965), pero le conferimos una estimación más precisa al considerar dos elementos: la productividad laboral en la entidad comparada con la del país (ventaja revelada de productividad), y la ventaja por diferenciales de salarios (ventaja revelada salarial). Más adelante mostramos la fórmula que expresa la suma de ambas ventajas.

En otras palabras, la competitividad de Guanajuato puede verse en la comparación de cada actividad respecto de dos factores: $a$ ) la estimación de la productividad laboral de cada actividad en el estado con respecto a la nacional $\left(\mathrm{VA} / \mathrm{L}^{*}\right)$; y b) lo mismo en la comparación del salario promedio de la actividad en el estado con el promedio nacional $\left(\mathrm{w} / \mathrm{L}^{*}\right)$. Ambas medidas en conjunto nos acercan a la competitividad relativa o revelada de la actividad en el estado $\left(\mathrm{VA} / \mathrm{L}^{* *}\right)$. El mejor resultado puede ser la ganancia de competitividad en actividades comerciables expuestas a competencia. ${ }^{?}$

pagados. El Directorio SIEM 2007 de empresas en ese municipio tampoco la registra, por lo que no pudimos acercarnos a una explicación más puntual.

${ }^{9}$ La diversidad de formas de acercarse a la competitividad de las actividades y las regiones permite suponer un alto grado de discrecionalidad al estimarlas. Por ejemplo, en la nota 17 se da cuenta de una estimación más agregada por entidades que deja a Guanajuato en mala comparación con otras. 
Definición de competitividad de actividades líderes en Guanajuato:

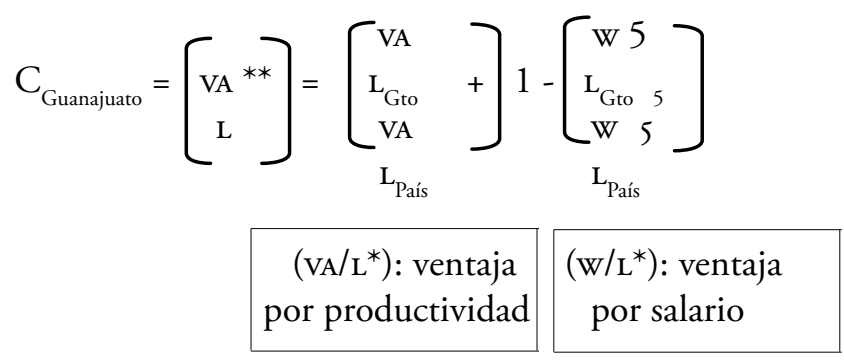

A manera de apreciación introductoria, adelantamos que en el estado de Guanajuato encontramos una mezcla peculiar de sectores tradicionales y otros de muy reciente arraigo. Los casos más interesantes en cuanto a la dinámica reciente de la competitividad están, sin duda, entre unas pocas ramas competitivas que destacan en todo sentido, tanto en importancia como en la dinámica de creación de empresas y de empleo; algunas logran crecer conservando altos márgenes de competitividad, complementando ganancias tanto por productividad como por diferenciales en los salarios.

Entre las ramas de mayor importancia y dinamismo habría que distinguir por su alta competitividad a las de alimentos y autos. En alimentos, los lácteos y panaderías logran indicadores de desempeño muy favorables: aumentan el número de empresas y de empleo, sin sacrificar su ventaja de productividad $50 \%$ por encima del promedio nacional. ${ }^{10}$ Automotores, en la influencia determinante de la General Motors (GM) en Silao, también aumentan empleo y mantienen altos estándares de productividad relativa, más de tres veces la del país, a pesar de las crecientes presiones de la competencia internacional en el sector durante el nuevo siglo (cuadro 3).

Otras actividades que muestran buen desempeño competitivo son electrodomésticos y metálicas básicas de hierro y acero, con indicadores de competitividad muy favorables respecto de la media nacional $(1.7 \mathrm{y}$ 2.6, respectivamente), pues crecen en empleo aunque ha disminuido el número de empresas. Como casi todos los bienes de capital, aun los de consumo doméstico, la primera de ellas puede tener una apreciación de particular importancia en la visión del sistema de innovación: forman parte de los proveedores especializados altamente apreciados por su inno-

${ }^{10}$ Los productos lácteos (rama 3115) se eslabonan con la importante producción de leche del ganado bovino en la entidad. La actividad principal en Guanajuato es la elaboración de queso, crema, mantequilla y yogur que alcanza 35.3\% del va en todo el país. El precio índice de la leche de Guanajuato está por debajo de la media nacional, lo que puede explicar la preferencia por elaborar derivados de lácteos sobre el envasado directo. 
vación. ${ }^{11}$ Las actividades de hierro y acero, por otra parte, probablemente van ligadas a la dinámica del cluster de automotores, lo que podría ser otra razón a considerar en la política industrial hacia la consolidación del mismo. La industria de bebidas también mejora su competitividad, pero lo hace fundamentalmente sacrificando la mitad de su fuerza de trabajo, en medio de una recomposición de las líneas de negocio para consumo local que la integran. ${ }^{12}$

En otras ramas, el desempeño es francamente poco favorable. Entre ellas destacaríamos al calzado, en su integración con la industria del cuero. El cuero-calzado conserva aún una importancia innegable en Guanajuato, pero evidencia serios problemas para resistir las presiones competitivas internacionales, por lo que su evolución es un tanto incierta. La producción se ha mantenido en el mismo nivel durante la década, pero es más preciso señalar que el calzado cayó durante el primer lustro, para recuperarse en el segundo, a costa del cierre de muchas empresas y de puestos de trabajo. ${ }^{13}$ Este resultado tal vez puede tomarse como indicación tentativa de una reestructura exitosa, a pesar de la pérdida de empleos. Un patrón similar, aunque sin cierre de empresas, corresponde a derivados de petróleo en Salamanca, sin que se pueda desconocer la influencia del regazo protector de Pemex como empresa del Estado.

Los no comerciables que incluyen principalmente servicios y comercio, algunos de ellos de alta estima por su valor social, se repiten con importancia moderada en Guanajuato como en cada entidad, dado que en mayor grado la oferta local crea su propia demanda en los servicios educativos, profesionales comunes, de salud, servicios de empleo, restaurantes y hoteles y en la distribución de básicos.

\subsection{La dinámica y la competitividad de las actividades en el estado}

Retomando el análisis pormenorizado para las actividades importantes en el estado, podemos destacar las tendencias de competitividad neta y supervivencia de cada una con los indicadores resumidos en el cuadro 3.

\footnotetext{
${ }^{11}$ Véase Pavitt (1984) y Dutrénit y Capdevielle (1993) con respecto a México. Los proveedores especializados son particularmente apreciados por su efecto en la difusión de las innovaciones en las estructuras económicas modernas.

${ }^{12} \mathrm{El}$ cierre de varias embotelladoras de refrescos se ve compensado por la creación de muchos establecimientos de agua purificada. En estos casos, el censo engloba actividades muy heterogéneas, por lo que es imprescindible descender el análisis al nivel de clases censales de seis dígitos (Unger, 2009).

${ }^{13}$ Como se aprecia en los cuadros de Unger (2009), las tasas de contracción del cuadro 3 significaron al calzado y cuero una caída de 10,000 empleos entre 1998 y 2003. Las prendas de vestir también tuvieron una pérdida considerable de 4,000 empleos. Estas últimas son más bien otro caso de tendencias inciertas, pues aumentan aceleradamente los empleos y el número de empresas durante el lustro 1993-1998, pero se contraen de manera significativa en los ańos 1998-2003 (cuadro 3).
} 
Cuadro 3

Competitividad y dinámica de las actividades principales ${ }^{\mathrm{a}}$ en Guanajuato, 2003-1993

\begin{tabular}{|c|c|c|c|c|c|c|c|c|}
\hline \multirow[t]{2}{*}{ Actividad } & \multirow{2}{*}{$\begin{array}{l}V A \\
(\%)\end{array}$} & \multirow{2}{*}{$\begin{array}{c}L_{03} \\
\text { (miles) }\end{array}$} & \multirow[t]{2}{*}{$U E_{03}$} & \multicolumn{2}{|c|}{ Aumentos 03-93 } & \multirow[t]{2}{*}{$V A / L^{*}$} & \multirow[t]{2}{*}{$W L^{*}$} & \multirow{2}{*}{$\begin{array}{c}V A / L^{*}+ \\
\left(1, O-W / L^{*}\right)\end{array}$} \\
\hline & & & & $V A(\%)$ & $L(\%)$ & & & \\
\hline Manufactura total & 51.9 & 223.4 & 17,745 & * & * & 1.1 & 0.8 & 1.3 \\
\hline Autos y camiones & 16.1 & 3.5 & * & $*$ & $*$ & 3.4 & 0.8 & 3.6 \\
\hline Derivados petróleo & 5.5 & 5.4 & 14 & 130 & 118 & 1.2 & 1 & 1.2 \\
\hline Calzado & 4.5 & 58.6 & 2061 & 5 & 21 & 1.1 & 1.1 & 1 \\
\hline Productos lácteos & 3 & 6.8 & 813 & 579 & 105 & 1.5 & 0.6 & 1.9 \\
\hline Autopartes & 2.7 & 10.1 & 27 & 999 & 375 & 1.3 & 0.7 & 1.6 \\
\hline Panadería y tortillas & 1.9 & 15.5 & 3,952 & 40 & 50 & 1.5 & 1.1 & 1.4 \\
\hline Electrodomésticos & 1.9 & 5.2 & 9 & 350 & 184 & 1.7 & 1 & 1.7 \\
\hline Bebidas & 1.9 & 2.8 & 136 & 130 & -41 & 1.6 & 0.8 & 1.9 \\
\hline $\begin{array}{l}\text { Productos de hierro } \\
\text { y acero }\end{array}$ & 1.3 & 0.9 & * & 999 & 560 & 2.7 & 1 & 2.6 \\
\hline Prendas de vestir & 1.2 & 17.4 & 971 & 209 & 147 & 0.9 & 0.9 & 1 \\
\hline $\begin{array}{l}\text { Curtidos de cuero } \\
\text { y piel }\end{array}$ & 1 & 8.3 & 569 & 14 & 15 & 1.2 & 0.9 & 1.3 \\
\hline $\begin{array}{l}\text { Conservación de } \\
\text { alimentos }\end{array}$ & 1 & 10.4 & 58 & 28 & -13 & 0.4 & 1 & 0.5 \\
\hline Productos de plástico & 1 & 8 & 203 & 212 & 246 & 0.7 & 0.7 & 1 \\
\hline Productos químicos & 1 & 2.4 & 53 & -32 & 16 & 0.6 & 0.7 & 0.9 \\
\hline Infraestructura total & 6.4 & 45.2 & 665 & * & * & 0.2 & 0.7 & 0.5 \\
\hline Construcción & 1.8 & 24.5 & 333 & 999 & 999 & 1 & 0.8 & 1.2 \\
\hline Energía eléctrica & 1.8 & 3.7 & * & * & * & 0.5 & 1.1 & 0.4 \\
\hline Obras e instalaciones & 1.4 & 11.4 & 332 & 999 & 999 & 1.1 & 1.1 & 1.1 \\
\hline Agua & 1 & 3.7 & * & * & * & 0.6 & 0.9 & 1.7 \\
\hline Servicios total & 14 & 190.8 & 46,439 & $*$ & $*$ & 0.4 & 0.6 & 0.8 \\
\hline $\begin{array}{l}\text { Restaurantes y } \\
\text { hoteles }\end{array}$ & 2 & 44.7 & 11,972 & 57 & 87 & 0.9 & 0.9 & 1 \\
\hline Servicios de empleo & 1.4 & 7.8 & 53 & 999 & 999 & 1.7 & 0.9 & 1.8 \\
\hline $\begin{array}{l}\text { Educación básica, } \\
\text { media }\end{array}$ & 1.2 & 20 & 835 & 56 & 136 & 0.7 & 0.8 & 0.9 \\
\hline Contabilidad & 1.1 & 7.4 & 795 & 267 & 161 & 1.1 & 0.9 & 1.2 \\
\hline Comercio total & 27.7 & 270.7 & 85,011 & * & * & 0.8 & 0.8 & 1 \\
\hline Materias primas & 2.9 & 13.9 & 2,478 & 41 & 42 & 0.9 & 0.9 & 1 \\
\hline Alimentos (menor) & 2.7 & 70.4 & 36,169 & 17 & 35 & 0.9 & 1 & 0.9 \\
\hline $\begin{array}{l}\text { Bebidas y tabaco } \\
\text { (mayor) }\end{array}$ & 2.6 & 9.9 & 161 & 86 & 60 & 0.8 & 1 & 0.9 \\
\hline Alimentos (mayor) & 2.2 & 9.6 & 595 & 110 & 87 & 0.9 & 0.9 & 1.1 \\
\hline Tiendas & 1.9 & 15.4 & 593 & 142 & 184 & 1.1 & 0.9 & 1.2 \\
\hline $\begin{array}{l}\text { Vehículos y } \\
\text { refacciones }\end{array}$ & 1.7 & 10.2 & 2,036 & 11 & 58 & 1 & 0.9 & 1.1 \\
\hline $\begin{array}{l}\text { Autotransporte } \\
\text { de carga }\end{array}$ & 1.5 & 11.2 & 1,593 & * & 61 & 0.9 & 0.9 & 1 \\
\hline Ropa y calzado & 1.4 & 27.9 & 13,412 & 109 & 167 & 0.9 & 0.8 & 1 \\
\hline $\begin{array}{l}\text { Combustibles } \\
\text { (menor) }\end{array}$ & 1.3 & 9.2 & 701 & 216 & 249 & 0.9 & 1.3 & 0.6 \\
\hline $\begin{array}{l}\text { Artículos de salud } \\
\text { (menor) }\end{array}$ & 1 & 8.4 & 2,614 & 234 & 123 & 1.2 & 1.2 & 1 \\
\hline
\end{tabular}

Notas: ${ }^{a}$ En caso de asterisco por ausencia de datos o por cuidado de confidencialidad, se asume valor (0). Col4 $\left(\mathrm{vA} / \mathrm{L}^{*}\right)$ : la relación $(\mathrm{VA} / \mathrm{L})$ actividad de Guanajuato entre $(\mathrm{VA} / \mathrm{L})$ actividad país. $\operatorname{Col} 5\left(\mathrm{w} / \mathrm{L}^{*}\right)$ : la relación $(\mathrm{w} / \mathrm{L})$ actividad de Guanajuato entre $(\mathrm{w} / \mathrm{L})$ actividad país. Col6 $\left(\mathrm{va} / \mathrm{L}^{* *}\right)$ : competitividad neta.

Fuente: Banco de México, dgcnesyp.inegi.gob.mx/cgi-win/bdieintsi.exe/NIVL10. 
En lo sucesivo, intentamos dar claridad a la exposición de diferentes casos, integrando los tres indicadores principales: la competitividad destacando los casos de competitividad mayor a 1.0, importancia que se denota en tres rangos ( $>1.0 \% ; 1.0-2.6 \% ;>2.7 \%)$ y el efecto en el empleo.

En ese cuadro de crecimiento de los empleos y de niveles de competitividad se pueden distinguir algunas ramas manufactureras con los mejores resultados a lo largo de la década 1993-2003: autos, lácteos, autopartes, hierro y acero, electrodomésticos, panadería y bebidas. La última constituye un caso particular que consigue muy alta competitividad, pero a costa de perder empleos. En todas ellas se logra crecer y competitividad neta superior a la media nacional. ${ }^{14}$ Las tres primeras en competitividad se cuentan entre las de mayor importancia. Otros casos de este tipo corresponden a construcción y obras, aunque los criterios de su contabilidad son todavía poco consistentes y no confiables para considerarlos en este análisis.

Los casos más exitosos de manufacturas muestran índices de competitividad neta superiores a 1.4 (uno indica la media nacional), con creación de nuevos empleos y comúnmente con nuevas empresas. Las otras situaciones menos exitosas, por rezago en la competitividad relativa, pueden haber tenido también cierre de empresas o pérdida de empleos, en particular durante el lustro más reciente: derivados de petróleo, calzado, cuero y piel, prendas de vestir, conservación de alimentos, productos de plástico y productos químicos. Algunas de ellas son casos híbridos de tendencias que oscilan hacia arriba y abajo, que habrán de tomar mejor claridad al hacer un análisis más puntual por municipios.

La tendencia para servicios y comercio es muy diferente: durante la década es bastante más homogénea en todos los aspectos, con mayores tasas de crecimiento aunque en condiciones de competitividad un tanto más modestas. ${ }^{15}$ Dada la condición de no comerciables en cuanto a estar poco expuestos a la competencia desde otras entidades y localidades, el desempeńo al menos a la par del promedio nacional para estos sectores, puede ser una señal de acompañamiento sano al desarrollo del estado. En todo caso, valdría señalar como posibles excepciones favorables en Guanajuato a las actividades de servicios de empleo, contabilidad y tiendas. Un caso opuesto de rezago relativo en competitividad corresponde al

${ }^{14}$ El coeficiente de correlación entre el crecimiento de empleos y la competitividad durante la década, y sobre todo en el último lustro, es positivo y significativo (Anexo II). La advertencia o salvedad obligada a destacar por su importancia es el de autos y camiones, pues logran el mayor índice de competitividad neta en 2003, junto con aumento de empleos (8\%), en un entorno de actividad de la rama a la baja (va de 2003 a 1998: -7.6\%), como se observa en la gráfica iI.

${ }^{15} \mathrm{La}$ tendencia general se expresa en el Anexo ir en un índice de correlación entre cambio de empleo y competitividad (0.795) altamente significativo. Las actividades de restaurantes y hoteles y servicios de empleo se refieren en esa gráfica a datos de 1998-2003. 
comercio minorista de combustibles, aunque los otros comercios y servicios muestran desempeńos muy favorables en el resto de los indicadores. ${ }^{16}$

\section{Vocación y competitividad de los municipios: las actividades principales}

\subsection{Tipología de las ramas por ventaja competitiva}

En Guanajuato encontramos actividades importantes por producción y empleo cuyas fuentes de competitividad nos permiten definir ventajas reveladas de muy diversa naturaleza. A partir de lo importante, es posible explorar también las características de las actividades competitivas, incluyendo su grado de complementariedad o independencia relativa.

Hay diversos criterios para clasificar las actividades por sus condiciones de competitividad. En atención a la disponibilidad más común de datos se da preferencia inicial a la clasificación sectorial más conocida, que hemos venido usando, la que separa a las manufacturas de otras actividades que pueden ser del sector primario y del comercio y los servicios del sector terciario. En lo sustantivo de este trabajo, volveremos a los municipios con esa clasificación.

Partiendo de los datos duros de producción, productividad y salarios, se pueden añadir otros criterios más cualitativos para considerar el tipo de ventajas reveladas, sean las basadas en recursos naturales o en ventajas de otra naturaleza. Las actividades de cada entidad pueden asociarse a ventajas competitivas de diferente origen, a saber: actividades con ventajas de base en recursos naturales locales, ${ }^{17}$ actividades con ventajas asignadas por localización de subsidiarias importantes de grandes transnacionales o corporativos, ventajas atribuidas a la actividad productiva directa del estado (como productor, proveedor, comprador u otras), y ventajas inherentes a las actividades de comercio y servicios que se distinguen por su condición de no comerciables (al margen de su valor social amplio y necesario). La competitividad de estas últimas quedará muy acotada a cada uno de los espacios locales. ${ }^{18}$ La expecta-

${ }^{16}$ Una explicación más puntual del comercio de combustibles podría ser mediante la comparación del rubro de combustibles de Guanajuato (o León) con los referentes nacionales de las gasolineras del Distrito Federal y otras grandes metrópolis.

${ }^{17}$ Las participaciones más destacadas en otros estados de México suelen ser de actividades basadas en recursos naturales: minerales, alimentos, prendas y en particular en Guanajuato, cuero y calzado. Cabe aclarar que en las cifras consideradas no se incluye el sector agropecuario porque no se considera en los Censos Económicos empleados. De incluirse, las actividades relacionadas con los recursos naturales cobrarían mayor importancia. La identificación de actividades con estos criterios de ventajas de diferente naturaleza proviene de un estudio previo (ғссут, 2006).

${ }^{18}$ Hay muchas otras formas de aproximarse a la competitividad económica de las regiones. Una de ellas muy común es hacerlo por comparación. Por ejemplo, un ejercicio comparando del cambio 
tiva es que estos criterios aporten nuevos y mejores elementos para el diseño de políticas.

En general, las ramas importantes y con ventajas reveladas de Guanajuato comparten una tendencia favorable a la especialización relativa en muy pocas localidades, como intentamos mostrar con las estimaciones más detalladas de actividades y municipios. Éstas integran la parte más sustantiva del ejercicio empírico.

\subsection{Desempeño y competitividad de actividades en municipios principales}

En esta sección damos cuenta de tres aspectos. En primer término destacamos una segunda condición de la mayoría de las actividades importantes, en virtud de que la producción de cada una se encuentra muy concentrada en pocos municipios. Un segundo paso sitúa la evolución de las actividades importantes en los municipios principales con algunos rasgos estilizados de la organización industrial y que tienen efecto en la evolución de cada una de ellas. El tercer aspecto se refiere a la competitividad en cada localidad.

En Guanajuato continúa la concentración de importancia en pocos municipios, lo que es un patrón común a todas las entidades federativas. En este estado el análisis de los municipios importantes puede quedar delimitado a siete de ellos, que representan proporciones muy significativas de la producción de las 32 actividades definidas como principales. En el cuadro 4 se muestra que las actividades conforman dos grupos de características muy diferentes.

1. Actividades importantes y muy concentradas en uno o, a lo sumo, dos municipios y que dan indicios de especialización competitiva muy focalizada.

2. El resto de las actividades muy diversificadas que se repiten en muchas localidades con importancia moderada en cada una, aludiendo a las características usuales de los no comerciables que atienden a las necesidades básicas de la población que habita en cada localidad.

Antes de dar paso al análisis individual para cada municipio, a continuación tratamos los casos más notables y representativos del grupo de

de las entidades mexicanas entre 1988 y 1998 deja a Guanajuato en condición de estado perdedor, al considerar separadamente los componentes de cambios denominados estructurales y los diferenciales. Le hacen compañía en esa condición perdedora de competitividad los estados del sur-sureste, el Distrito Federal, Jalisco y los no fronterizos del norte (Sobrino, 2005: 170). 


\section{Cuadro 4}

\section{Importancia en va de las actividades principales por municipio, 2003}

\begin{tabular}{|c|c|c|c|c|c|c|c|c|}
\hline Actividad & León & Silao & Celaya & Irapuato & Salamanca & Guanajuato & Allende & Otro. \\
\hline Manufactura & & & & & & & & \\
\hline $\begin{array}{l}\text { Autos y camiones } \\
\text { Derivados de }\end{array}$ & --- & 100.0 & --- & --- & --- & --- & --- & 0.0 \\
\hline petróleo & 3.1 & --- & --- & -- & 96.9 & -- & -- & 0.0 \\
\hline Calzado & 99.0 & --- & --- & --- & --- & --- & --- & 1.0 \\
\hline Productos lácteos & 4.9 & -- & 3.6 & 83.3 & 0.7 & 0.5 & 2.9 & 4.1 \\
\hline Autopartes & --- & 59.5 & 39.8 & --- & --- & --- & --- & 0.7 \\
\hline $\begin{array}{l}\text { Panadería y } \\
\text { tortillas }\end{array}$ & 12.2 & 0.6 & 10.0 & 64.9 & 1.7 & 0.9 & 2.1 & 7.6 \\
\hline $\begin{array}{l}\text { Electrodomés- } \\
\text { ticos }\end{array}$ & --- & --- & 100.0 & --. & --. & --- & --- & 0.0 \\
\hline Bebidas & 88.9 & -.. & 4.4 & 3.0 & -.- & -.- & -.. & 3.7 \\
\hline $\begin{array}{l}\text { Productos de } \\
\text { hierro y acero }\end{array}$ & --- & --- & 99.9 & -.- & --. & --- & --- & 0.1 \\
\hline Prendas de vestir & 12.9 & --- & 14.0 & 26.1 & 6.5 & -- & 24.6 & 15.9 \\
\hline $\begin{array}{l}\text { Curtido de } \\
\text { cuero y piel }\end{array}$ & 100.0 & --- & --- & --- & -- & --- & --- & 0.0 \\
\hline $\begin{array}{l}\text { Conservación de } \\
\text { alimentos } \\
\text { Productos de }\end{array}$ & 9.1 & 0.9 & 34.6 & 44.8 & 1.2 & -- & 0.5 & 8.9 \\
\hline & 78.1 & --- & 19.2 & 1.4 & 0.4 & --- & --- & 0.9 \\
\hline $\begin{array}{l}\text { químicos } \\
\text { Infraestructura }\end{array}$ & 13.3 & --- & 27.5 & 4.5 & 38.9 & --- & --- & 15.8 \\
\hline Construcción & 53.8 & 1.5 & 28.0 & 4.4 & 2.9 & 5.5 & 1.0 & 2.9 \\
\hline Energía eléctrica & --- & -- & -- & --- & -- & 63.2 & 36.8 & 0.0 \\
\hline $\begin{array}{l}\text { Obras e instala- } \\
\text { ciones }\end{array}$ & 29.4 & 2.0 & 5.2 & 13.8 & 3.5 & 38.4 & 1.0 & 6.7 \\
\hline $\begin{array}{l}\text { Agua } \\
\text { Servicios }\end{array}$ & 53.2 & 2.0 & 21.6 & - & 5.7 & 5.4 & 3.2 & 8.9 \\
\hline $\begin{array}{l}\text { Restaurantes y } \\
\text { hoteles }\end{array}$ & 36.2 & 3.0 & 12.7 & 9.9 & 4.0 & 9.3 & 7.2 & 17.7 \\
\hline $\begin{array}{l}\text { Servicios de } \\
\text { empleo } \\
\text { Educación }\end{array}$ & 49.5 & 32.8 & - & 2.0 & 10.9 & - & 3.3 & 1.5 \\
\hline básica, media & 47.6 & 1.2 & 18.4 & 13.8 & 4.5 & 2.6 & 4.2 & 7.7 \\
\hline $\begin{array}{l}\text { Contabilidad } \\
\text { Comercio }\end{array}$ & 90.2 & - & 3.5 & 2.6 & -- & -- & -- & 3.7 \\
\hline Materias primas & 44.9 & 1.4 & 15.9 & 12.9 & 4.5 & 0.7 & 3.0 & 16.7 \\
\hline $\begin{array}{l}\text { Alimentos } \\
\text { (menor) } \\
\text { Bebidas y tabaco }\end{array}$ & 36.9 & 2.2 & 13.2 & 10.6 & 3.6 & 3.5 & 7.8 & 22.2 \\
\hline $\begin{array}{l}\text { (mayor) } \\
\text { Alimentos }\end{array}$ & 20.0 & 6.0 & 18.4 & 11.1 & 5.9 & 1.1 & 9.3 & 28.2 \\
\hline (mayor) & 41.0 & --- & 20.1 & 11.8 & 4.4 & - & 3.8 & 18.9 \\
\hline $\begin{array}{l}\text { Tiendas } \\
\text { Yehículos y }\end{array}$ & 55.4 & 1.0 & 13.2 & 14.4 & 3.5 & 5.4 & 1.6 & 5.5 \\
\hline $\begin{array}{l}\text { Vehiculos y } \\
\text { refacciones } \\
\text { Autotransportes }\end{array}$ & 56.5 & 1.9 & 18.5 & 8.0 & 3.6 & 3.1 & 1.9 & 6.5 \\
\hline de ca & 45.8 & --- & 23.2 & 7.9 & 12.3 & --- & --- & 10.8 \\
\hline $\begin{array}{l}\text { Ropa y calzado } \\
\text { Combustibles }\end{array}$ & 48.4 & -- & 8.2 & 8.1 & 2.6 & -- & -- & 32.7 \\
\hline $\begin{array}{l}\text { (menor) } \\
\text { Artículos de salud }\end{array}$ & 37.6 & 1.8 & 21.2 & 8.5 & 4.2 & 1.9 & 2.3 & 22.5 \\
\hline (menor) & 32.9 & -- & 11.0 & 14.1 & 4.7 & 3.6 & -- & 33.7 \\
\hline
\end{tabular}

Nota: Allende (cluster): comprende los municipios de Dolores Hidalgo, San José Iturbide, San Luis de la Paz y Allende.

Fuente: Censos Económicos de 2003. 


\section{Gráfica III \\ Participación de uno o dos municipios en las actividades principales (2003, miles de millones)}

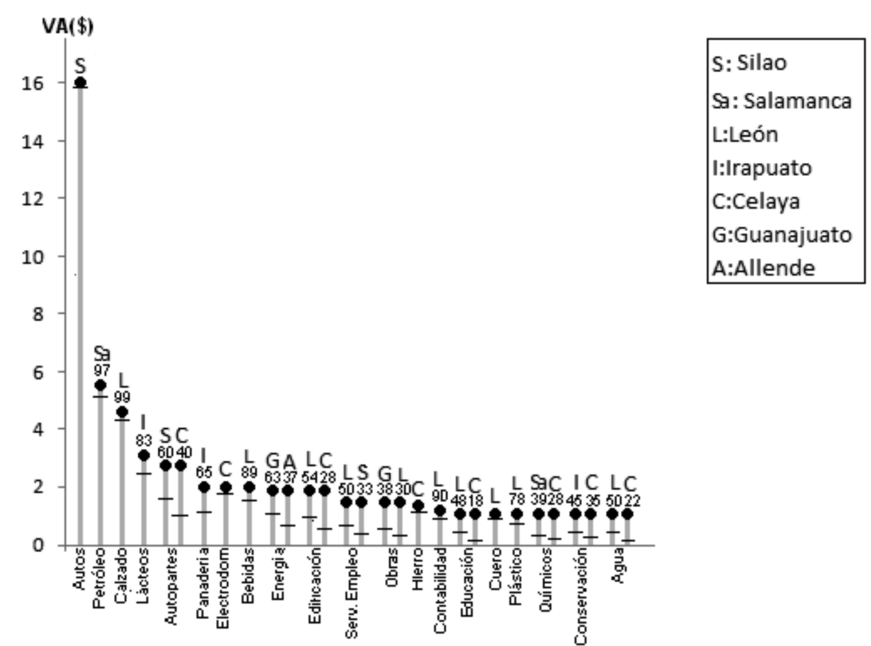

Nota: El número es el procentaje en ese municipio (por ejemplo, León $=99 \% \mathrm{del}$ calzado).

Fuente: Censos Económicos de 2003.

actividades importantes según su grado de concentración o dispersión geográfica.

En la gráfica III se muestra claramente un patrón de concentración municipal que predomina entre las actividades principales de manufacturas e infraestructura, así como en unas pocas de servicios modernos. Desde esa perspectiva, los municipios son de dos tipos.

1. León y Celaya se distinguen porque alcanzan importancia en una amplia variedad de actividades. La importancia de León es considerable en calzado, cuero, despachos de contabilidad, bebidas y productos de plástico. La participación de Celaya en electrodomésticos, hierro y acero y autopartes es notable, también es importante en otros rubros como construcción, educación, agua y productos químicos.

2. Los otros municipios reflejan especializaciones más puntuales. Silao en autos, autopartes y servicios de empleo; Irapuato destaca en lácteos, pan industrial y conservación de alimentos; Salamanca en derivados de petróleo y productos químicos; y Allende y Guanajuato en energía e infraestructura. 
Con los antecedentes podemos enriquecer el análisis particularizado a cada municipio con otros aspectos de su evolución durante la década y sus logros de competitividad. El propósito es añadir explicaciones intuitivas a la dinámica empresarial.

La estimación de importancia se complementa con las dos aproximaciones de dinamismo que refieren a la organización industrial de los municipios en cada actividad: crecimiento (o disminución) de empresas y de empleos. La primera da idea de competencia que se compacta o extiende, la segunda de la dinámica de la actividad en conjunto que puede llevar de la mano la creación de nuevos empleos al aumentar la producción, pero también puede ser al contrario. Otras explicaciones adicionales a estas pautas de la organización productiva pueden provenir de considerar el papel de las firmas dominantes (transnacionales, estatales, corporativos), pues hay ventajas competitivas que son asignadas por las propias firmas: podríamos denominarlas ventajas por decreto de empresa. También juegan cierta influencia otros aspectos de la naturaleza tecnológica de la actividad y su grado de comerciabilidad, aspectos todos subyacentes al origen de la ventaja competitiva que anticipamos unas líneas arriba.

Finalmente, el tercer aspecto de efecto competitivo que se observa en la evolución de cada actividad en los municipios, se expresa en las mismas dos variables analizadas en el ámbito estatal: $a$ ) la estimación de la productividad laboral de las actividades en cada municipio con respecto a la de la actividad en todo el país; y b) lo mismo en la comparación del salario promedio de la actividad en el municipio con el promedio nacional. Ambas medidas en conjunto nos darán una primera indicación de la competitividad relativa o revelada de la actividad en la localidad.

Demos paso al análisis individual de los municipios importantes, entendiendo que la suma de los demás representa poco más de 35 municipios pequeños y de menor importancia.

\subsubsection{Las ramas competitivas en León}

León es con mucho el principal centro económico del estado. Es por demás natural tomarlo como un municipio razonablemente diversificado, ${ }^{19}$ considerando también que hace un cluster de relaciones sectoriales estrechas con los dos vecinos, San Francisco y Purísima del Rincón, muy

\footnotetext{
${ }^{19}$ En una versión anterior, León era el líder indiscutible entre los pocos municipios diversificados en Guanajuato. Éstos incluyen a tres de los grandes de la entidad: León, Celaya e Irapuato, que están entre los cuatro mayores del estado (Silao se interpone en segundo lugar por tamańo del producto). En este grupo las manufacturas son el sector más importante (42.3\%), pero los servicios y el comercio también alcanzan representatividad con 18 y $34.1 \%$, al desarrollarse polos urbanos con economías de interesante dinámica intersectorial.
} 
anclado en el cluster industrial del cuero-calzado. Los porcentajes correspondientes a la actividad de los tres grandes sectores en el cuadro 6 están un tanto más cargados a servicios y comercios, en parte por la recesión que en los últimos años ha caracterizado al calzado y también por la natural proliferación de todo tipo de servicios que acompaña al desarrollo de una conurbación grande y poblada como ésta.

En cuanto a las ramas a destacar individualmente por importancia respecto a la economía del propio municipio, en 2003 todavía son calzado y curtido de cuero (13.2 y $3 \%$ ), bebidas ( $4.9 \%$ sobre todo en refrescos y agua purificada), construcción (3\%), productos de plástico $(2.2 \%)$, muchas actividades de servicios y comercio orientadas a satisfacer las demandas derivadas del crecimiento de la población, así como la multiplicación de actividades de soporte o acompañamiento a la actividad económica, como restaurantes y hoteles, despachos de contabilidad, servicios de empleo, comercios de todo tipo y servicios de transporte. ${ }^{20}$

La dinámica de estas ramas en León durante 1993-2003 impone los resultados para la economía estatal, dada la importancia dominante de este municipio respecto de las ramas en el estado, como se muestra en el cuadro 4. En cuatro de las ramas de manufacturas suele exceder $75 \%$. Esto indica un patrón de especialización municipal en algunas manufacturas, por economías de aglomeración y escala en la mayoría de las plantas fabriles. El resultado agregado, no obstante, es una dinámica de crecimiento de manufacturas mucho más moderada para León que la de las actividades principales ( 44.4 y $219.5 \%$ en el estado, respectivamente). Las ramas de mayor dinamismo están en otras partes. Es muy conocido el efecto que la competencia internacional ha impuesto a las industrias del calzado y cuero leonesas.

Ahora bien, las principales cifras del cuadro 5 para la década resumen la dinámica competitiva de León. Se incluyen las tendencias de empleo, creación o cierre de empresas y la situación de competitividad que guardan las actividades principales en 2003. Esas cifras son muy ilustrativas de la diversidad de situaciones que prevalecen entre las actividades en León.

Algunas tienen más éxito que otras, pero las empresas manufactureras más importantes han tenido cierres y despidos laborales significativos, en especial en el lustro 1998-2003. Véase en particular la dinámica que siguen las industrias de calzado, cuero y bebidas. En realidad, las ramas exitosas en todo sentido a lo largo de la década son pocas: construcción, tiendas, así como venta de vehículos y refacciones entre las importantes. Otras exitosas en competitividad y crecimiento de empleos son despachos de

\footnotetext{
${ }^{20}$ Otras actividades también relevantes en León, pero que no alcanzan lugar individualmente entre las 32 actividades importantes antes seleccionadas son productos de hule, herrerías, servicios profesionales y telecomunicaciones.
} 
contabilidad y servicios de empleo. En el primer rubro hay contracción del número de empresas durante el segundo lustro, pero el notable aumento de empleos implica que los grandes despachos continuaron con muy buen desarrollo: absorbieron en parte a los empleados de los desplazados de otras oficinas. También importante en competitividad, pero a costa de reducir empleos, está la industria de bebidas, cuya recomposición supuso cerrar algunas embotelladoras de refrescos y desarrollar nuevos negocios de agua purificada.

Un segundo grupo de ramas cuya competitividad está a la par de la media nacional, incluye a la del calzado ${ }^{21}$ (es de suponer que la media nacional se impone desde aquí), productos de plástico y muchas otras no comerciables en alimentos, artículos de salud, comercios de materias primas, ropa y calzado y restaurantes y hoteles. Las demás caen por debajo de la media de competitividad nacional, al tiempo que algunas entre las importantes del municipio también pierden empleos y empresas en el lustro 1998-2003, como puede verse para fabricación de calzado, comercio de materias primas, de bebidas y tabaco, y otros menores de conservación de alimentos.

La diversidad de situaciones de competitividad en León se corresponde con diferentes razones de fondo. Hay actividades, como el cuero y el calzado, que han venido perdiendo nichos de mercados nacional e internacionalmente, tanto porque se han deteriorado las ventajas originales de base en el recurso natural (el cuero disminuye calidad ante otros competidores), como porque tiene rezagos en las capacidades de diseño para los mercados de alto margen. En otras líneas de productos, la competencia por vía de costos salariales se ve afectada por las grandes economías de escala de origen en China y similares. Algunas empresas zapateras grandes se han reestructurado en respuesta, pero el resultado todavía es incierto.

Otras actividades se han compactado en oligopolios internacionalizados globalmente, con demandas avaladas sobre todo por los mercados locales y regionales. Es el caso de refrescos en el rubro de bebidas. Por otro lado, el auge reciente del agua purificada embotellada y de relleno, contrasta en el sentido de dar pie a numerosos establecimientos en la cercanía de los mercados muy locales.

Los despachos contables en León, de buen desempeño en productividad profesional, sugieren una exitosa explosión de profesionales locales capaces, de la mano de una ventaja competitiva asignada desde grandes firmas globales que aprovechan menores salarios. Un caso de similitudes es el automotriz en Silao, que se analiza más adelante.

\footnotetext{
${ }^{21}$ La evolución más reciente del calzado es preocupante. La producción cayó durante el primer lustro, para recuperarse en el segundo, a costa del cierre de empresas y de alrededor de 10,000 puestos de trabajo.
} 


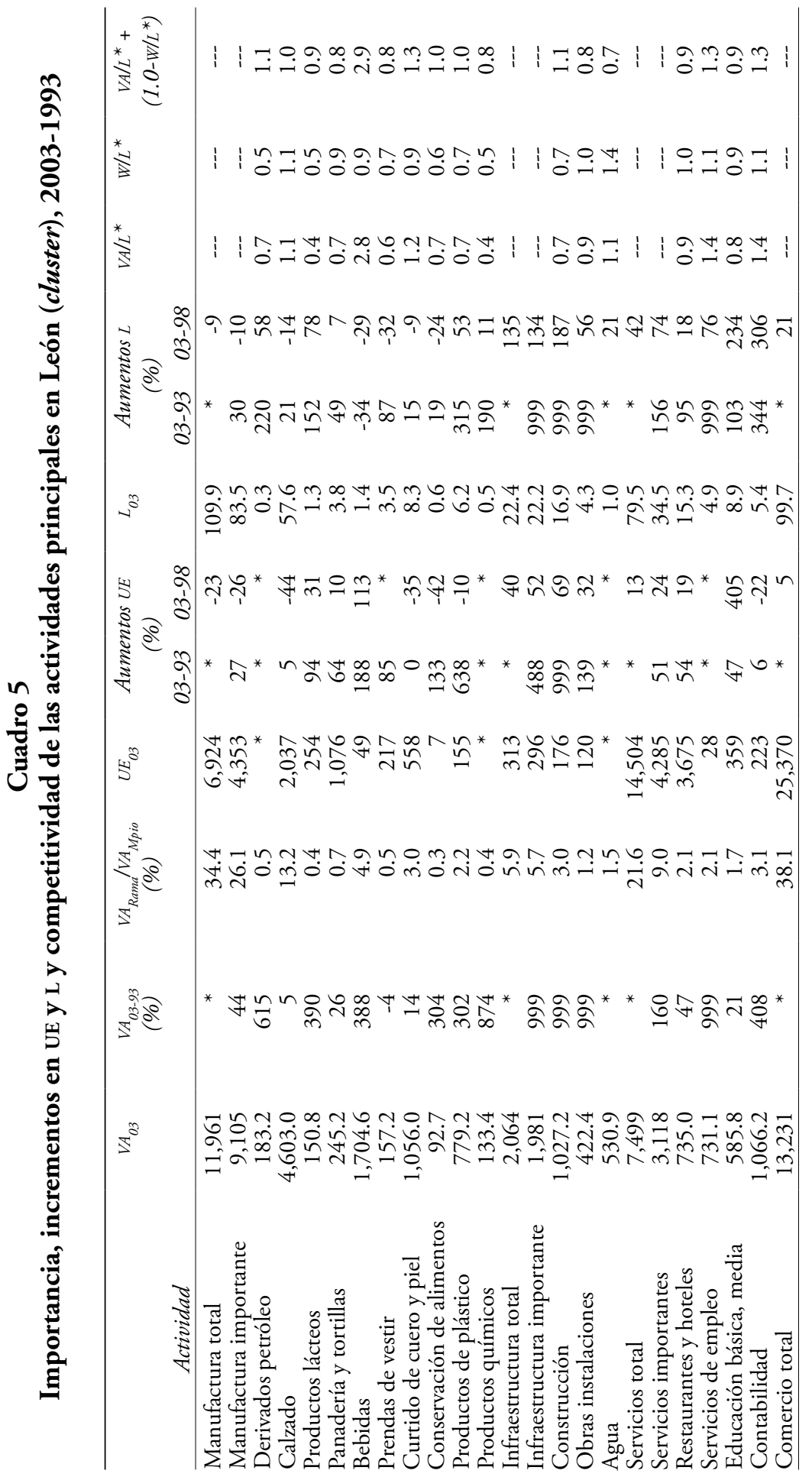




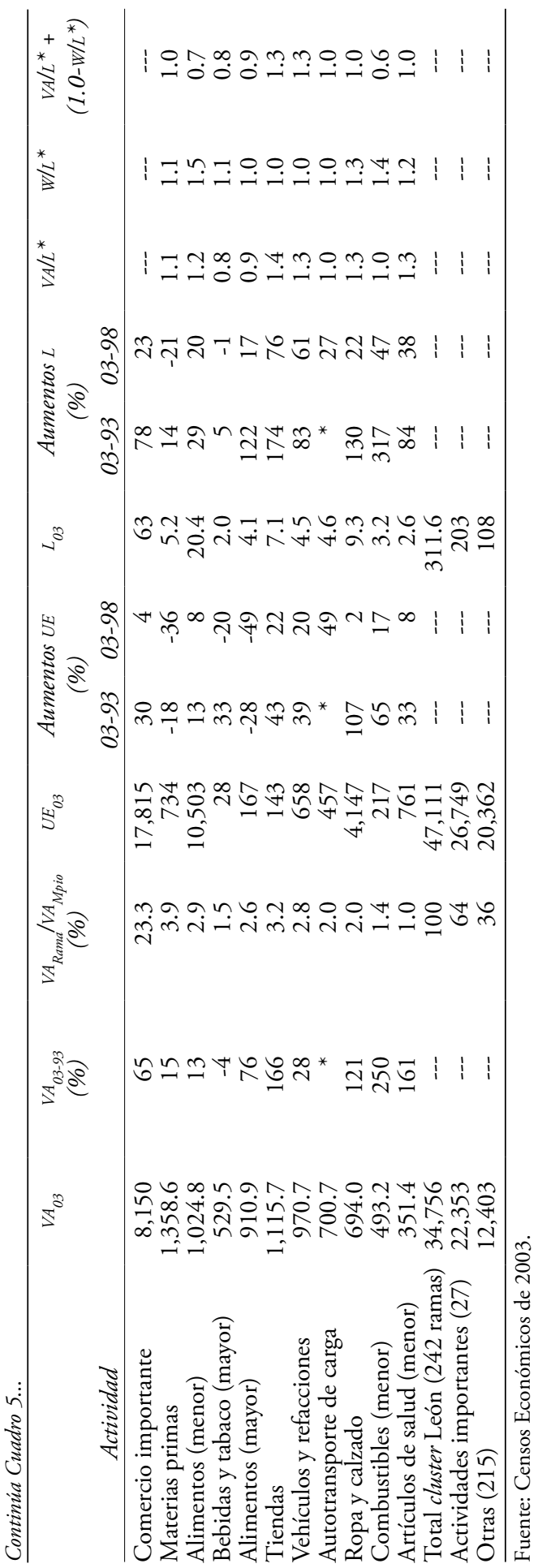




\subsubsection{Celaya, un municipio exitoso y diversificado}

Celaya conforma también un cluster económico de importancia, con más razón cuando se le suma la actividad de los municipios vecinos de Villagrán y Apaseo el Grande. La importancia de las manufacturas ha ido ganando terreno sobre los otros sectores, pues al igual que en Irapuato exceden en $50 \%$ su participación en el pIB municipal (cuadro 6). No obstante, algunos rubros de comercios y servicios más básicos también se han desarrollado para atender a la población de esta conurbación.

En Celaya, las ramas más destacadas individualmente por importancia respecto a la economía del propio municipio en 2003, son de instalación más bien reciente, encabezadas por electrodomésticos (13.4\%), hierro y acero $(9.2 \%)$ y autopartes $(7.5 \%)$; las dos primeras concentran en Celaya la totalidad de la actividad en el estado, en tanto que las autopartes representan $40 \%$ del total estatal, las cuales también tienen presencia en Silao (gráfica III). Otra media docena de ramas vinculadas a alimentos ${ }^{22}$ (sobre todo de comercialización y conservación de alimentos) y productos químicos y de plástico también alcanzan cierta importancia (cuadro 6). Los químicos tienen una dinámica de altas y bajas, no así los otros que crecen de manera más consistente. Otros servicios y comercios con buen crecimiento son los usuales de soporte al crecimiento poblacional: restaurantes y hoteles, educación media, algunos servicios financieros, comercios de todo tipo y servicios de transporte.

$\mathrm{Al}$ igual de lo observado en León, la dinámica de estas ramas importantes en Celaya sugiere un patrón de especialización municipal, principalmente en manufacturas, por economías de aglomeración y con plantas de gran escala. Los ejemplos más evidentes son electrodomésticos (la importancia de la planta de Mabe, con presencia en mercados de exportación), hierro y acero (Siderúrgica del Bajío), y en las autopartes y químicos dominantes en la planta fabril del cluster Celaya, cuya dinámica quizá está más acorde con la influencia de la ciudad industrial de Querétaro. El resultado agregado es una dinámica de crecimiento de manufacturas razonablemente buena que duplica el valor de la producción durante la década (165.3\% de crecimiento de las actividades principales). El mayor impulso al crecimiento de otras manufacturas en el estado proviene de Silao e Irapuato, como veremos, pero Celaya está respondiendo también con buen dinamismo, en especial después de 1998.

\footnotetext{
${ }^{22}$ La clase industrial de galletas y pastas (311820) impone al rubro panadería y tortillas cifras de muy poca competitividad. Al parecer se trata mayormente de expendios de venta de pan y pasteles. Tal vez también hay error de registro de los salarios que se estiman 1.7 veces de la media nacional en el cuadro 7 .
} 


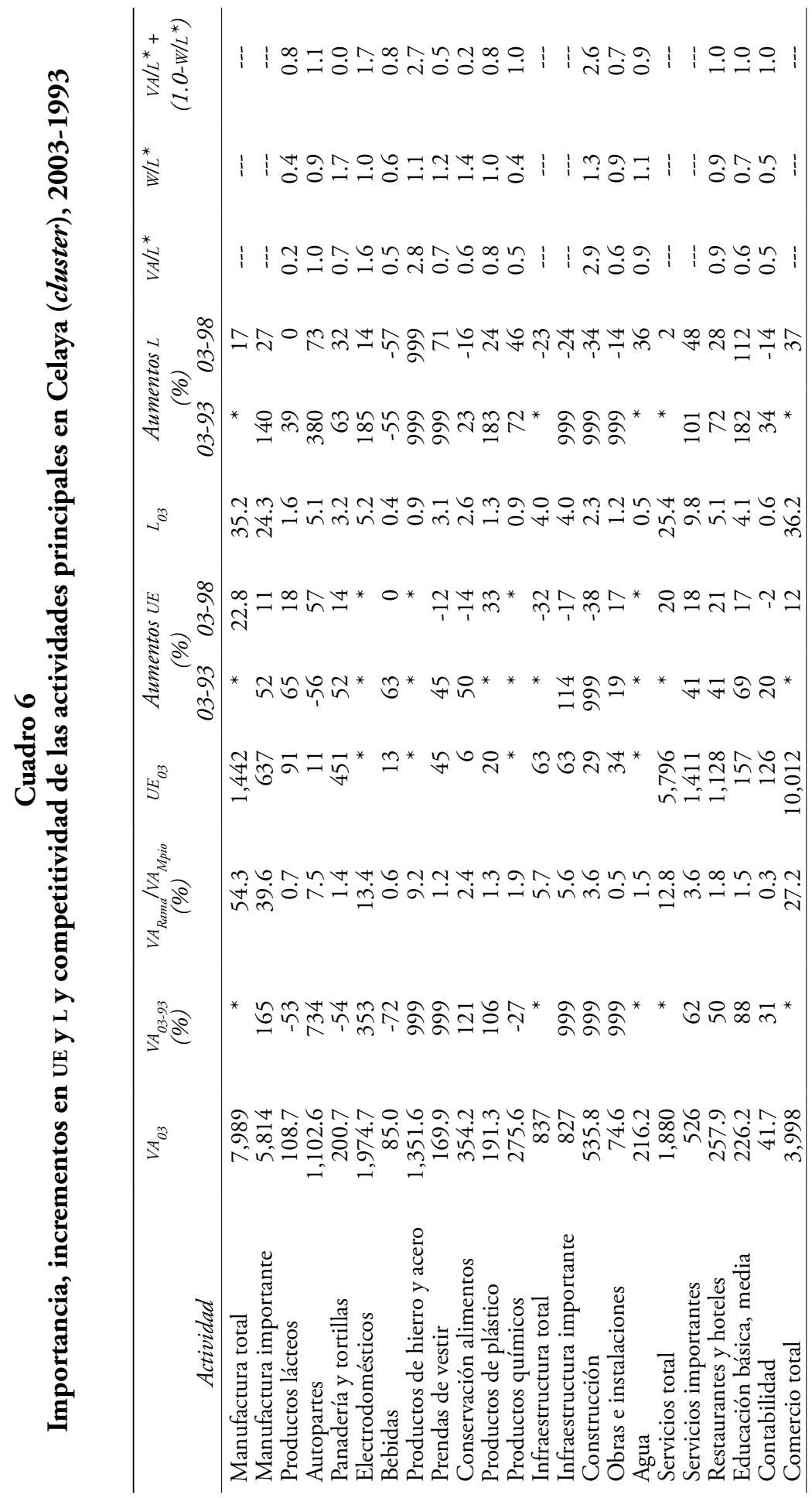




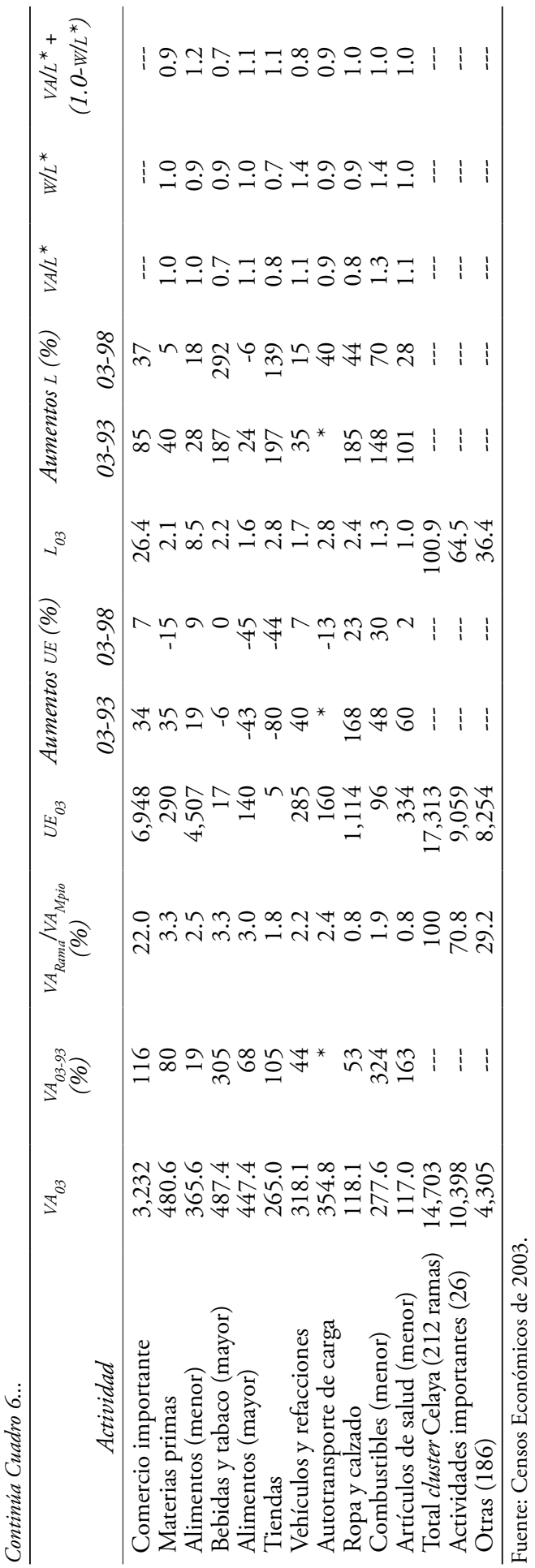


Como se mencionó, los comercios y servicios tienen desempeños más comparables entre los municipios por la propia naturaleza de esas actividades menos susceptibles de especialización espacial. En Celaya, como en otras concentraciones de la población y la geografía, se desarrollan con buen ritmo las actividades de construcción y otra infraestructura, restaurantes y hoteles, servicios financieros, educativos y muy notablemente la mayoría de los comercios.

El resumen de dinámica y competitividad para la década 1993-2003, incluyendo las tendencias de empleo, creación de empresas y la situación de competitividad que guardan en 2003, es más favorable en el caso de Celaya que en otros sitios, porque las ramas en problemas son pocas y de menor importancia. Las más notables tienen buen desempeño competitivo y de empleos, como los electrodomésticos, hierro y acero, autopartes, con alta competitividad. ${ }^{23}$ La construcción, ${ }^{24}$ productos químicos y la mayoría de los servicios y comercios se mantienen en una dinámica más o menos competitiva.

\subsubsection{El caso de Irapuato, un municipio de base en recursos naturales}

Irapuato también conforma un cluster económico importante, sólo superado por León, Silao y Celaya. Como en este último, las manufacturas han ido ganando terreno sobre los otros sectores: exceden en $54 \%$ su participación en el PIв municipal (cuadro 7). No obstante, algunos rubros de comercios y servicios más básicos, típicamente entre los no comerciables, también se han desarrollado para atender a sus pobladores.

Las ramas más destacadas individualmente por importancia respecto a la economía del propio municipio en 2003 están muy relacionadas con los recursos naturales de la región, de manera notable el procesamiento de alimentos. Productos lácteos (26.1\%), panadería industrial (13.4\%), conservación de alimentos (4.7\%) y prendas de vestir (3.3\%) suman la mitad del PIB municipal. Las dos últimas ocupan a cerca de 10,000 empleados, aunque en condiciones poco competitivas; en particular la industria del vestido ha experimentado cierres y pérdida de empleo, como en otras partes del país.

Las dos industrias líderes -lácteos y pan- destacan en todos sentidos, y en particular en competitividad (índices de competitividad neta de 11 y 6.3 ,

\footnotetext{
${ }^{23}$ La relación entre el aumento de empleos y la competitividad en las manufacturas de Celaya se destaca particularmente durante el último lustro: la correlación es positiva (0.7936) y significativa (Anexo iI).

${ }^{24}$ Las actividades de construcción, autotransporte, agua, prendas de vestir y obras se refieren (gráfica III) a datos del lustro 1998-2003.
} 
cuadro 7). Este desempeño está directamente asociado al rol de liderazgo que imponen dos grandes empresas: Kerry y Bimbo, respectivamente.

Los servicios y comercios de mejor crecimiento son los usuales de soporte al crecimiento económico y poblacional: restaurantes y hoteles, educación media y superior, algunos servicios profesionales, comercios de todo tipo y servicios de transporte (cuadro 7).

Como en los casos anteriores, la dinámica de estas ramas importantes en Irapuato sugiere un patrón de especialización municipal, principalmente en ciertos rubros de manufacturas, por facilidad de acceso a las materias primas que son procesadas cerca de su origen aprovechando mejores costos de transporte con economías de escala; esta ventaja competitiva es más evidente en las ramas de alimentos. El impulso al crecimiento manufacturero del estado desde Irapuato se basa en estas actividades y se expresa en una tasa de crecimiento de más de $200 \%$ en la década, que continuó con buen dinamismo después de 1998.

El resumen de dinámica y competitividad para la década 1993-2003, incluyendo las tendencias de empleo, creación de empresas y la situación de competitividad que guardan en 2003, es muy favorable en Irapuato en las ramas más importantes de alimentos, ${ }^{25}$ incluyendo excelentes indicadores de dinámica y competitividad para ellas y razonables para otras, como las de educación media, restaurantes y hoteles, y la mayoría de las tiendas comerciales y otros rubros de comercio. No obstante, otros rubros de manufacturas (prendas de vestir, químicos y bebidas) no han evolucionado igual, pues se han contraído notablemente durante el último lustro.

\subsubsection{Un municipio monomanufacturero: Silao}

Silao, al igual que Salamanca, es otro municipio importante del estado que se distingue porque es muy especializado. Su auge obedece a que fueron creados como iniciativas corporativas con capacidades competitivas de asignación por sus empresas líderes respectivas en ramas muy puntuales. El ensamble de autos y el procesamiento de petróleo y derivados, requieren concentrar en un determinado punto geográfico las capacidades productivas que son muy dependientes de operar con grandes escalas para desarrollar los niveles básicos de la competitividad de operación. En mayor medida, se trata de actividades cuyo devenir competitivo está decidido antes de instalar las plantas (ventaja competitiva decidida ex-ante).

Así, Silao es tal vez el caso extremo de un municipio monosectorial, centrado en la industria automotriz. La importancia de la producción de

\footnotetext{
${ }^{25}$ Estas ramas determinan un coeficiente de correlación entre el crecimiento de empleos y la competitividad en manufacturas durante la década, positivo (0.7687) y significativo (Anexo II).
} 


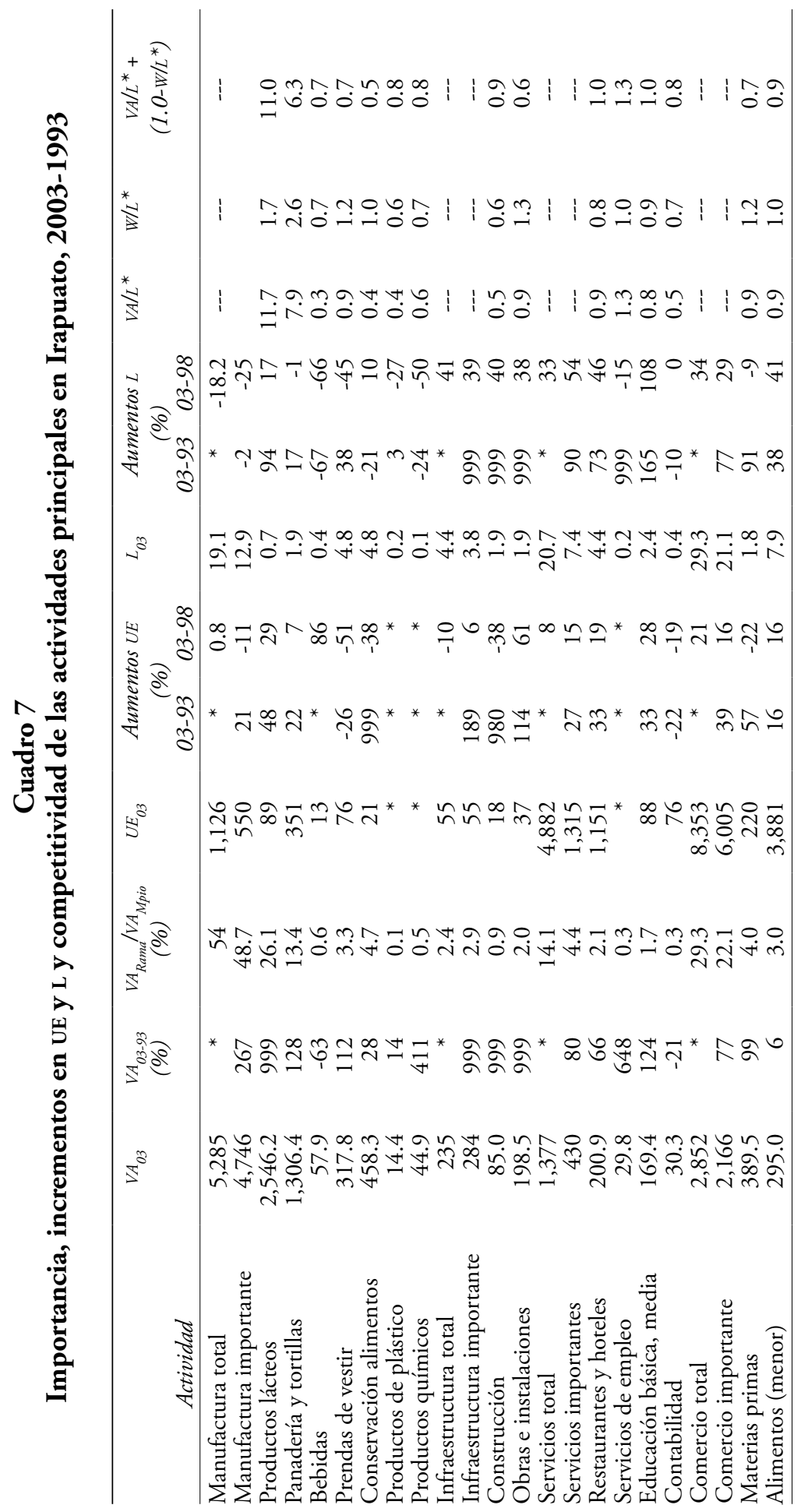




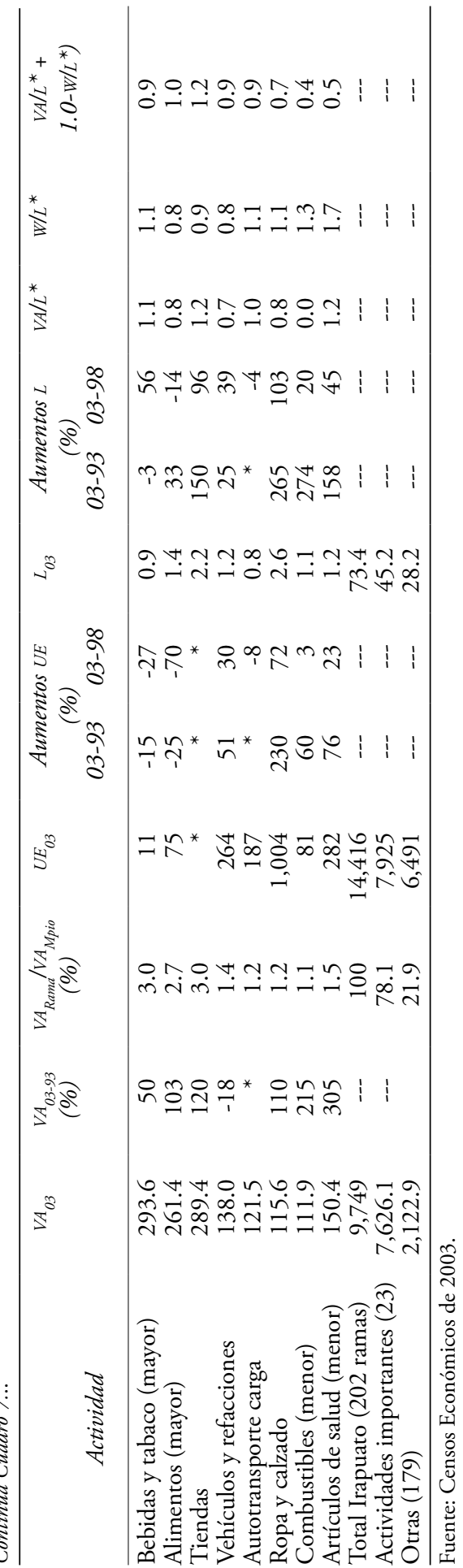


autos y autopartes dejan a todas las demás ramas en un papel marginal (83.7 y $8.3 \%$ del va municipal de 2003 , cuadro 8 ). La instalación de la planta de GM a mediados de los noventa todavía es relativamente reciente y se ha conservado en buena forma tecnológica; la competitividad de Silao (léase de esta planta) es 3.6 veces la media nacional. Más allá de los problemas internacionales que enfrenta esa empresa y la industria en general, se espera que este tipo de plantas de alta productividad, con personal entrenado y aun de salarios moderados respecto de otros países, sean instrumentales en sortear la crisis de los años próximos. ${ }^{26}$ La política pública estatal puede ser determinante para afirmar la especialización futura de esta localidad desde ahora, sumando recursos de formación de cuadros y mediante el fomento del desarrollo de capacidades de I\&D y similares.

Otras ramas se han desarrollado en Silao por acompañamiento obligado. La mayoría lo hace aumentando empresas y empleos a partir de prácticamente nada. Vale destacar tres ramas de servicios. La primera en importancia son los servicios de empleo con muy alto índice de competitividad, indicando tal vez la importancia del outsourcing laboral entre empresas transnacionales que han experimentado en casa las presiones de muchos empleos sindicalizados de alto costo (cuadro 8). Otras de acompañamiento predecibles son bienes raíces y, aunque de carácter delicado por sí misma, son los servicios de investigación y seguridad. El resto de las ramas crece sin distinguirse en la competitividad respecto del resto del país, es el caso de reparación de autos, restaurantes y hoteles, servicios profesionales, educación media y otros comercios y servicios.

\subsubsection{Otro municipio manufacturero de base petrolera: Salamanca}

Éste también es un caso extremo de municipio monosectorial, centrado en la industria de derivados de petróleo de Pemex. La importancia de la producción es dominante (65.4\% del va municipal de 2003, cuadro 9), aunque a lo largo del tiempo se han desarrollado muchas más actividades periféricas de comercio, servicios e infraestructura, en comparación con Silao. La planta de Pemex se ha conservado en aceptable situación tecnológica, con competitividad neta de 1.2 sobre la media nacional.

Como en otros casos, la política pública estatal puede ser determinante para afirmar la consolidación futura de esta localidad desde ahora, sumando recursos de formación de cuadros y capacidades de I\&D y similares, más allá de la apuesta coyuntural de atraer la nueva refinería que actualmente se disputa en el ámbito nacional.

\footnotetext{
${ }^{26}$ El seguimiento de la importancia de GM en Silao, el coeficiente de correlación entre el crecimiento de empleos y la competitividad en manufacturas durante la década, y sobre todo en el último lustro, es positivo y significativo (Anexo II).
} 


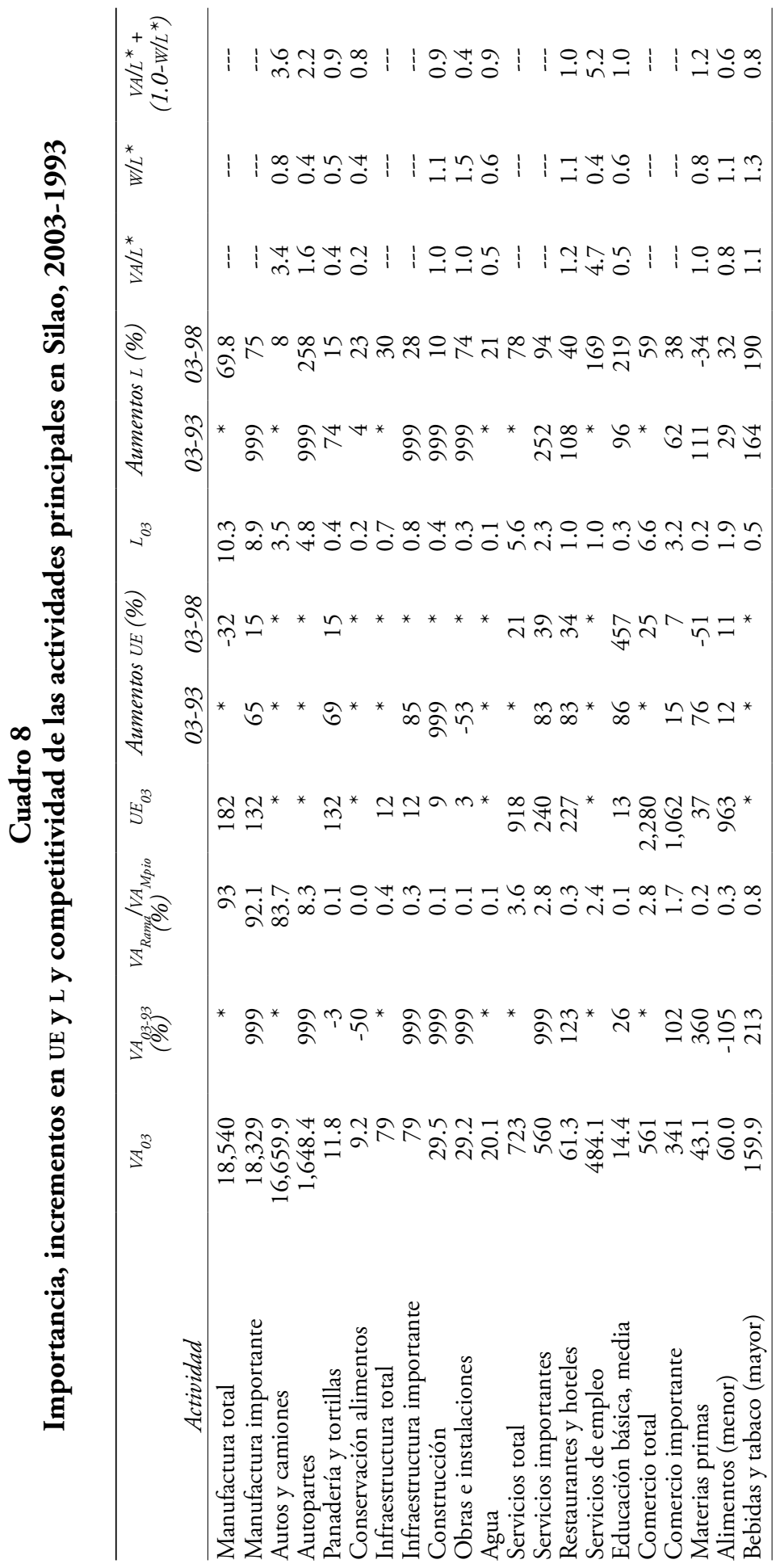




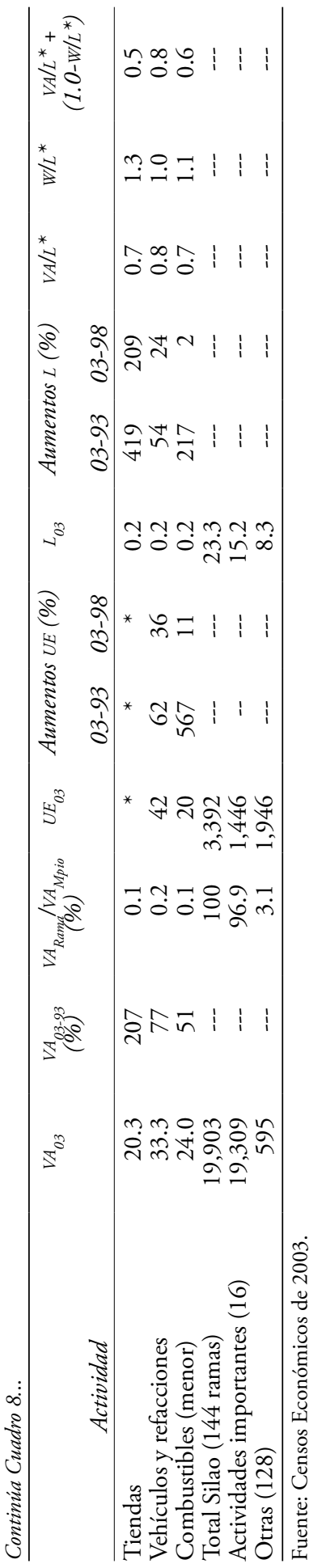




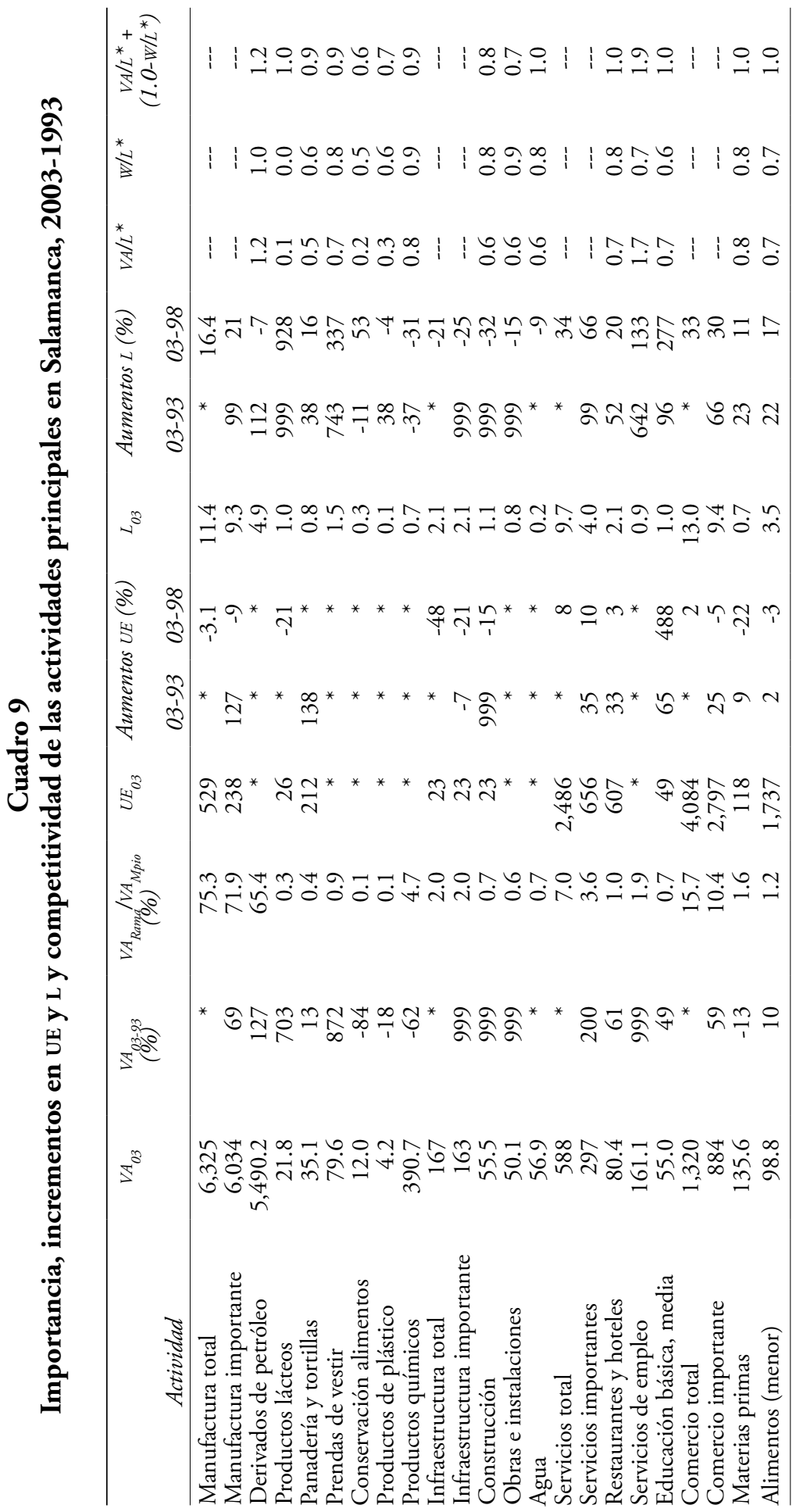




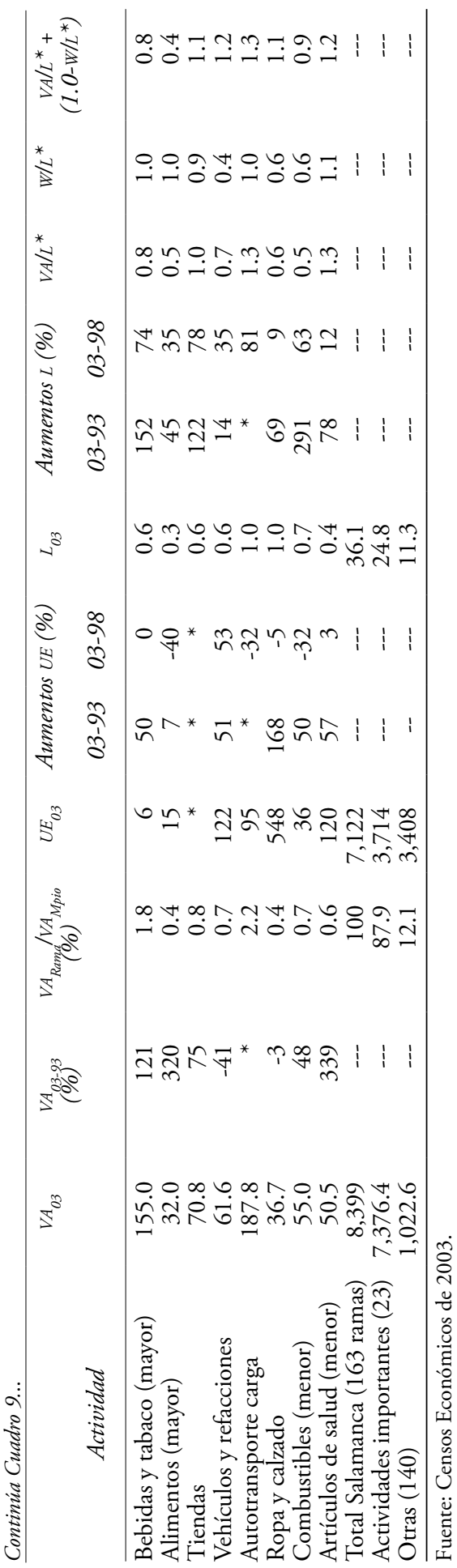


Otras ramas que se han desarrollado en Salamanca por acompañamiento natural son productos químicos, servicios de empleo, casas de cambio y autotransporte de carga, todos ellos con índices de competitividad razonablemente exitosos. ${ }^{27} \mathrm{El}$ resto se reparte de forma muy regular entre servicios y comercios de demanda local asegurada y predecible, sin distinguirse en la competitividad del resto del país, en actividades de restaurantes y hoteles, educación media y comercios de todo tipo.

\subsubsection{Guanajuato, un municipio de naturaleza propia}

La capital del estado se distingue por actividades de infraestructura y comerciales. Es el principal centro de abastecimiento de energía eléctrica del estado, junto con San Luis de la Paz, que aportan 63.2 y 36.8\% de la generación propia de energía, respectivamente (cuadro 4). La realización de obras, construcción y el servicio de abastecimiento de agua también alcanzan importancia considerable (cuadro 10). Por otra parte, asimismo destacan restaurantes y hoteles, tiendas y comercio de alimentos, salud y otros comercios. En todo caso, la importancia de manufacturas es muy menor.

La condición de competitividad de las principales actividades es muy cercana a la media nacional, como es de esperarse en estos rubros. El caso de energía eléctrica, con un índice de competitividad de 0.2 , seguramente refleja prácticas arbitrarias del registro de las facturaciones por parte de la Comisión Federal de Electricidad (CFE); es poco creíble que los 3,600 empleados en ese rubro y con salarios muy cercanos a la media (de hecho el salario promedio es 1.1 el del país), trabajen en condiciones de productividad tan alejadas de las prácticas nacionales. El caso contrario es de obras, probablemente por las mismas consideraciones de contabilidad, pero en este caso por sobrerrepresentatividad. Las tiendas son tal vez el único rubro de competitividad probada en ese municipio.

\subsubsection{Un municipio de vocación turistica: Allende}

En el municipio de Allende, con cabecera en San Miguel (y los municipios cercanos con los que integra un cluster común con Dolores Hidalgo, San José Iturbide y San Luis de la Paz), destacan muy notablemente los sectores de comercio y servicios. Las ramas de importancia crecen bien y son relativamente competitivas en relación con el país, aunque no todas, y en particular la energía, pueden presumir que están integradas al resto de la economía local. El motor más evidente del municipio son las ramas de

\footnotetext{
${ }^{27}$ El coeficiente de correlación entre el crecimiento de empleos y la competitividad en servicios y comercio durante la década es positivo y significativo (Anexo II).
} 


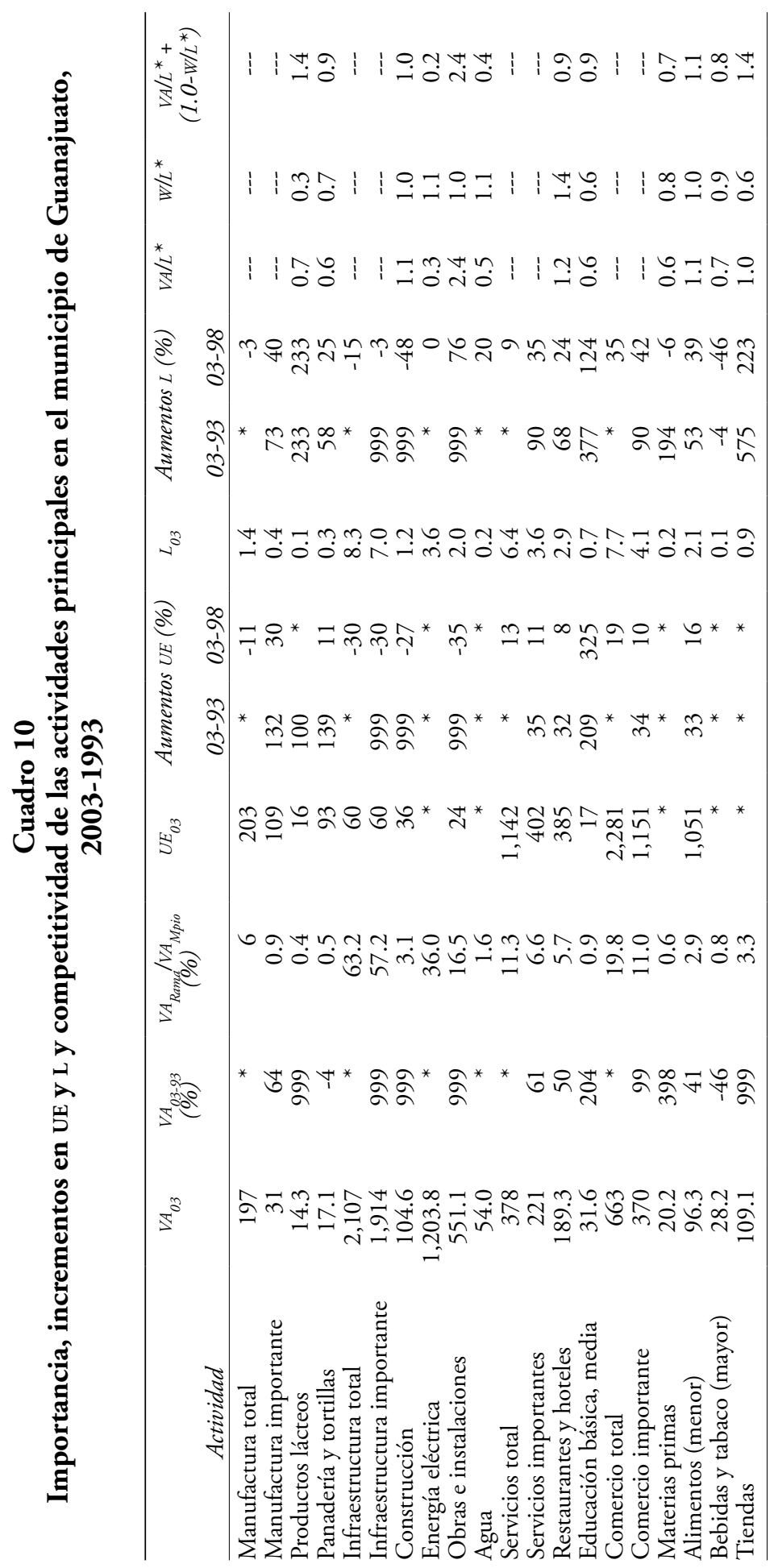




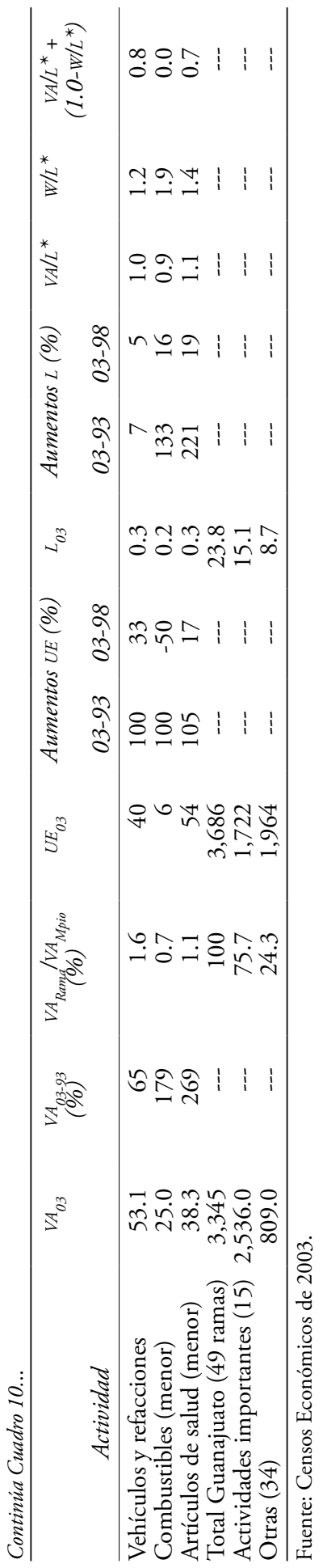


restaurantes y hoteles, más los encadenamientos comerciales y de servicios relacionados que las acompañan (cuadro 11). Éstas también son las de mayor competitividad neta, incluidos comercio de alimentos y bebidas, y comercio de materias primas. Las otras ramas, típicamente de no comerciables, subsisten en niveles medios sin mayor amenaza: ferreterías, reparación de autos, combustibles, educación media y panaderías. Entre las manufacturas, prendas de vestir y productos lácteos son ramas de cierta importancia individual, aunque los lácteos tienen muy baja productividad.

Dos casos excepcionales en este municipio (cluster) son la energía eléctrica y las prendas de vestir, ambos en San Luis de la Paz, con 36.8 y 24.6\% del PIB estatal de esos rubros, respectivamente. ${ }^{28}$ Ambos se disparan en cálculos de competitividad demasiado altos; la de energía eléctrica por la CFE, tal vez es en compensación con el subregistro del municipio de Guanajuato que antes reportamos, en tanto que las prendas de vestir al parecer tienen un error de reporte en los datos del Censo que sitúa a la productivi$\mathrm{dad}(\mathrm{vA} / \mathrm{L})$ en ese municipio casi 20 veces la del promedio estatal. ${ }^{29}$

\subsubsection{Municipios con otras vocaciones}

El resto de los municipios son de menor importancia y generalmente se orientan al sector primario y a las actividades comerciales en el centro poblacional del mismo. Los comercios y algunos servicios que se ofrecen en todas partes, son aquellos que gozan de una relativa protección como otros no comerciables, fincados como sucede con frecuencia a la necesidad de satisfacer las demandas de la población asentada en la cercanía de las cabeceras municipales.

\section{Conclusiones e implicaciones de política}

El examen de la vocación económica y la evolución competitiva de las actividades principales del estado de Guanajuato nos deja un mosaico compuesto de muy diversos componentes desde dos ángulos: las ramas de especialización y los municipios con liderazgo competitivo.

La caracterización de los municipios según la vocación sectorial es reveladora de diferencias sustantivas. Los municipios diversificados tienen una mejor dinámica y están más a salvo de oscilaciones bruscas por la propia y natural defensa de riesgos que se neutralizan. En cambio los manufactureros (Silao, Salamanca, San José Iturbide), usualmente mo-

\footnotetext{
${ }^{28} \mathrm{Al}$ parecer, las actividades de energía, prendas de vestir y construcción no reportan valores reales de competitividad.

${ }^{29}$ El Directorio SIEM de empresas en el estado no consigna prendas de vestir en San Luis de la Paz, excepción hecha de muchos comercios de ropa de tamaño pequeńo.
} 
nomanufactureros porque dependen de manera muy sustancial de una sola actividad (autos, petróleo, químicos), pueden tener gran exposición a los cambios de esas ramas que ponen en riesgo la viabilidad del municipio en conjunto. Los otros municipios se resguardan más en la defensa moderada de los comercios y servicios, actividades de naturaleza no comerciables y de primera necesidad.

La competitividad y el dinamismo del estado y los municipios en cada actividad, ya sea el aumento (o disminución) de empresas y del empleo, expresa el resultado de una competencia que se estrecha o extiende. En etapas posteriores será necesario dar seguimiento al rol que juegan las firmas dominantes (transnacionales, estatales, corporativos) y su disponibilidad para empujar en la dirección requerida. Esta disposición es indispensable para sumarse a las medidas que aproximan a la competitividad relativa o revelada de la actividad en la localidad.

La implicación más fina de estos resultados es que la política pública se debe orientar a apuntalar la especialización futura específica de cada una de estas localidades, sumando esfuerzos desde todos los ángulos -incluido el financiero, el desarrollo de infraestructura, la capacitación y formación de cuadros- para contribuir al desarrollo de las capacidades técnicas de I\&D y soportes similares a cadenas y clusters de sectores integrados.

Una política industrial a favor de ramas comerciables con competitividad y en condiciones de crecimiento, debe partir de lo específico y de mayor relevancia a cada situación. El análisis de ramas en el ámbito municipal descubre diferentes tipos de competitividad, contrastando entre competitividades asignadas y por productividad.

Un buen número de casos se pueden identificar como competitividades asignadas y garantizadas por la empresa, en cuyo caso la decisión fundamental es dónde se decide instalar la empresa. Este tipo de competitividad aplica para ramas tan disímiles como los autos en Silao (GM), derivados de petróleo en Salamanca (Pemex) y la panadería industrial en Irapuato (Bimbo). El imperativo de economías de escala determina por igual a empresas de propiedad transnacional (GM, Bimbo) como a plantas petroquímicas propiedad del Estado (Pemex). En estos casos toma tiempo desarrollar a los municipios como polos urbanos con economías intersectoriales dinámicas, a veces sin poder consumar su competitividad. Es evidente que la acción de política pública en estos casos debe ser más agresiva, congruente y persistente que en aquellas instancias en que el mercado se arregla por sí mismo. ${ }^{30}$

\footnotetext{
${ }^{30}$ En los casos asignados se puede incluir San José Iturbide como otro polo en ciernes de cierta similitud, por alojar una gran planta de jabones y limpiadores de otra empresa transnacional (Colgate Palmolive) con cobertura de mercado nacional y competitividad decretada por virtud corporativa.
} 


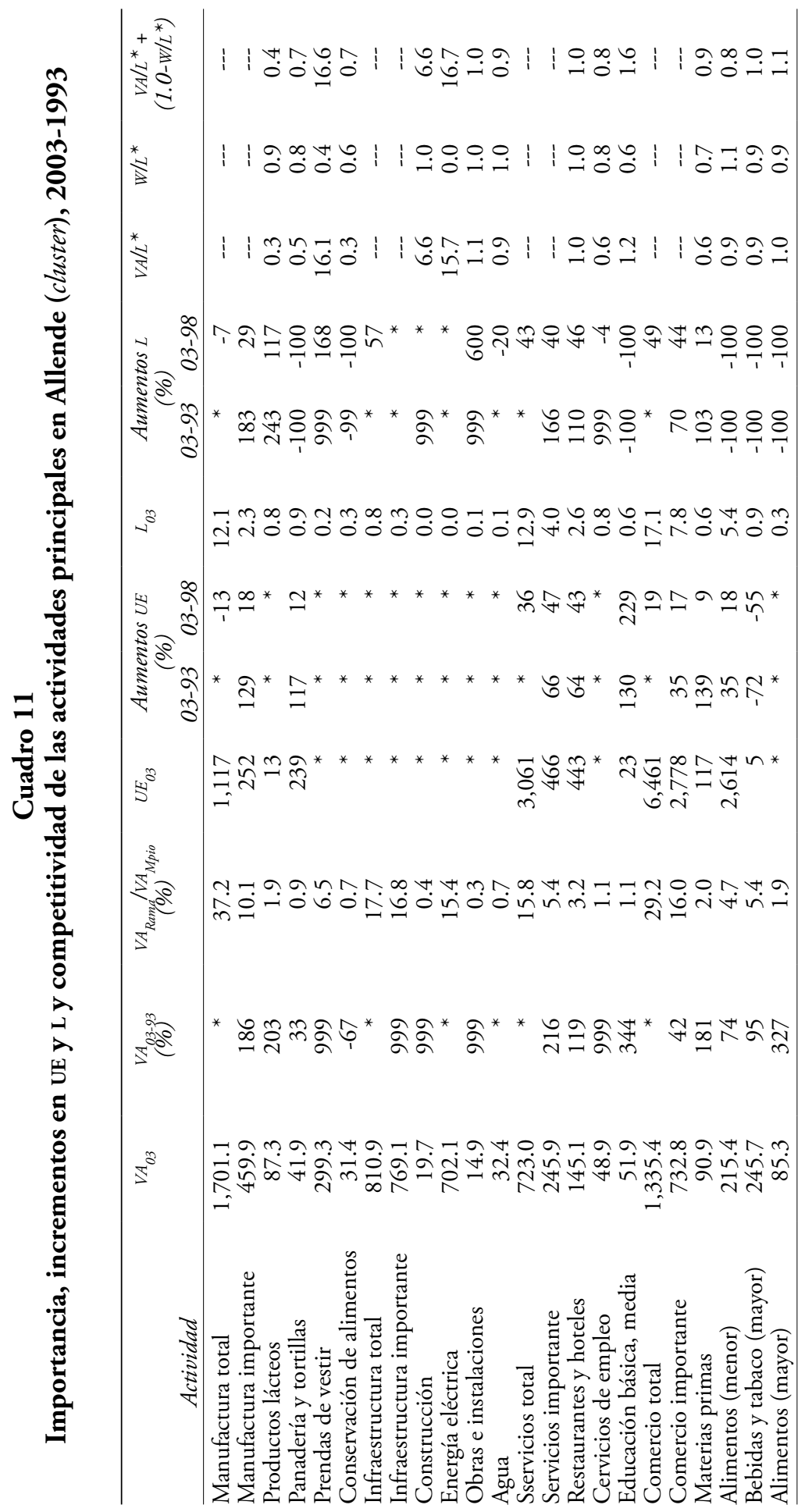




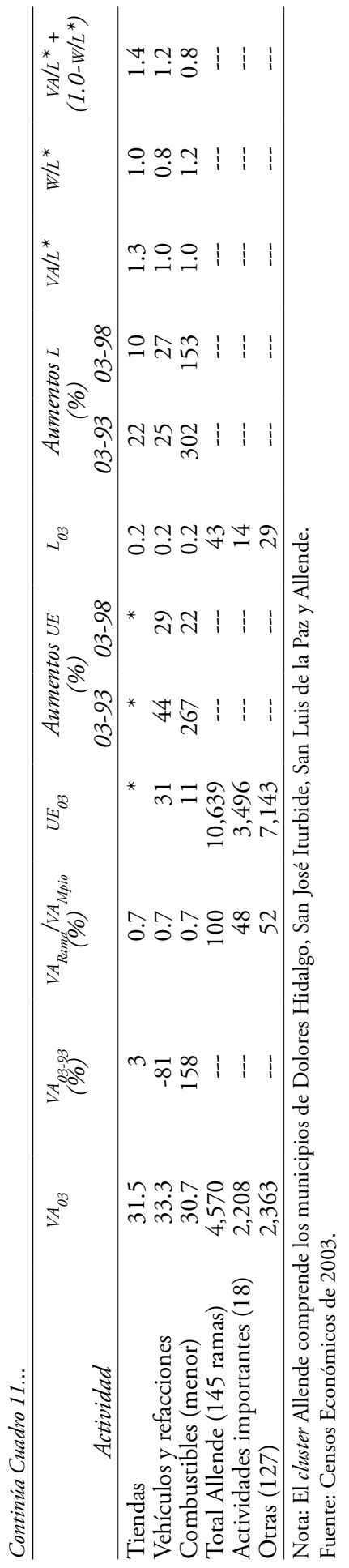


Otras ramas se desarrollan en entornos de mayor competencia entre empresas y diversas localizaciones, que a lo largo del tiempo logran ser competitivas por condiciones más típicas de mejorar la productividad y capitalizar otras ventajas mediante la integración de insumos y demandas de cercanía. La integración del cluster cuero-calzado en León y el desarrollo de las autopartes en Celaya son de este tipo. Las autopartes y, hasta cierto punto también los electrodomésticos, ambos en Celaya, parecen relacionados con las ventajas de proveeduría en hierro y acero, así como las derramas industriales por la cercanía de Querétaro.

En un sentido más general, si la idea es favorecer clusters competitivos con especializaciones regionales reveladas, algunos de los casos más destacados nos llevarían a buscar la integración de regiones más amplias que trascienden al propio estado de Guanajuato. Las sinergias de cuero-calzado del cluster León pueden considerar la inclusión de la ganadería de los Altos de Jalisco e Irapuato, como un caso centrado en Guanajuato. Otro caso es el desarrollo de Celaya bajo la influencia de derramas a partir de la base industrial de Querétaro. Con seguridad hay otros sitios en el país con un mayor potencial de integración del que reconocen los propios vecinos, pues las virtudes de muchos encadenamientos todavía no se comprenden suficientemente. 


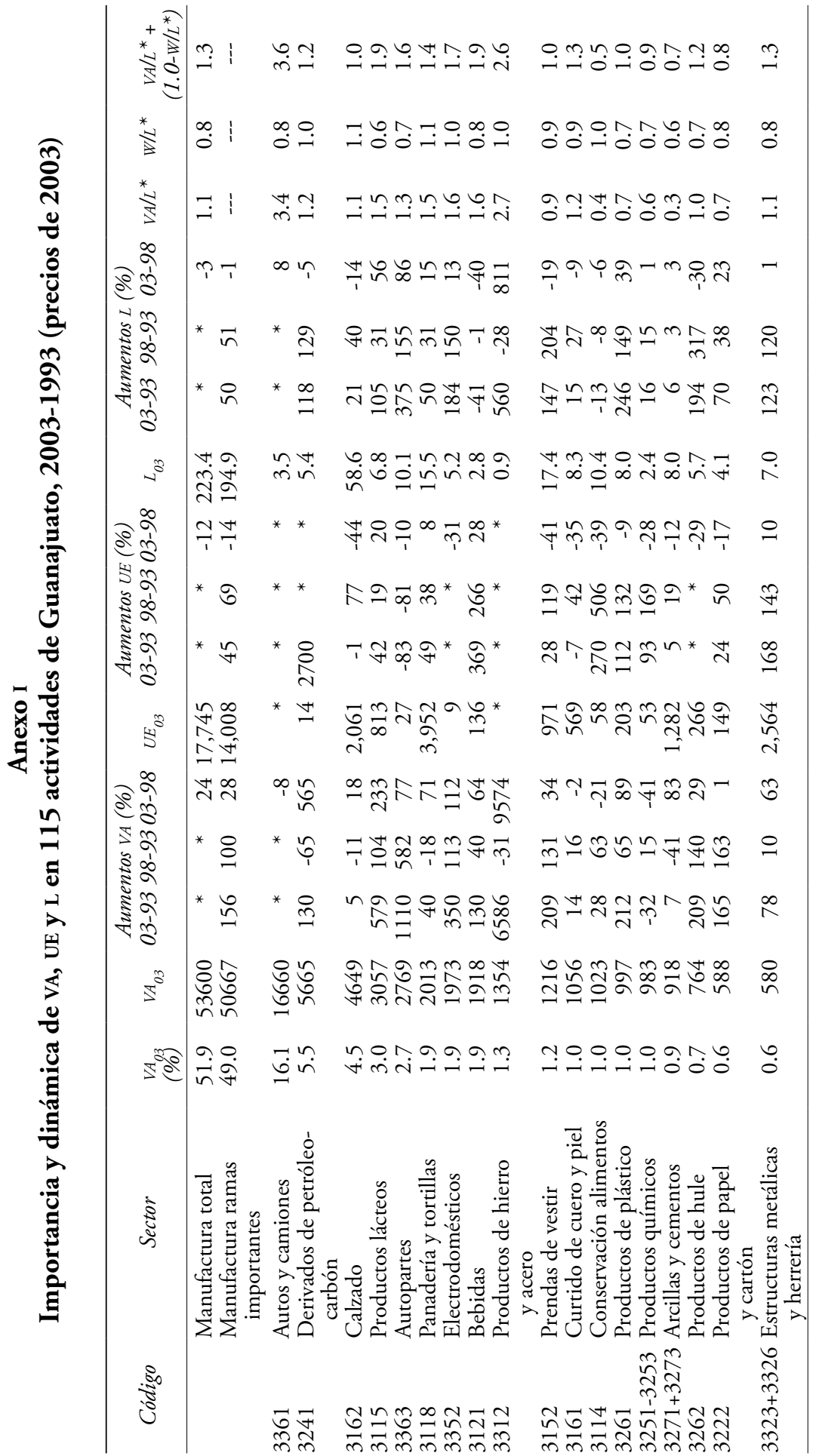




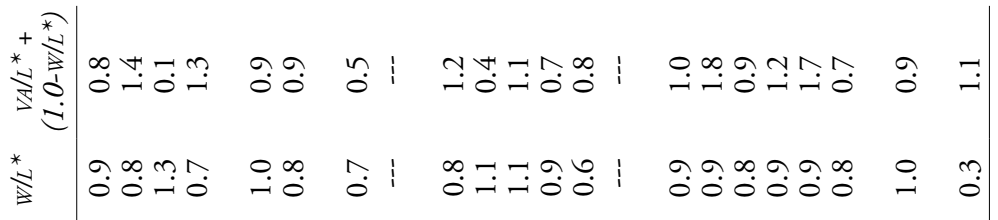

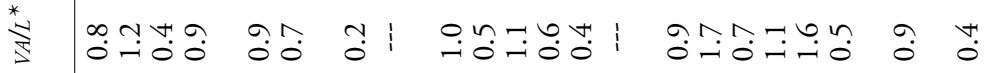

市

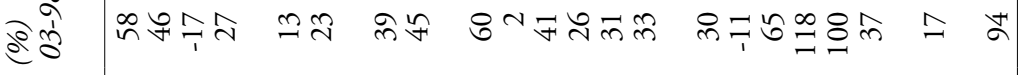

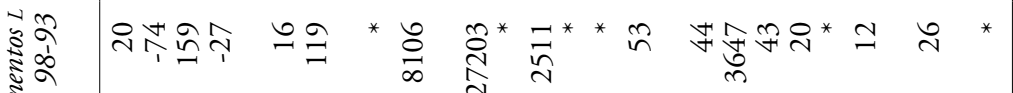

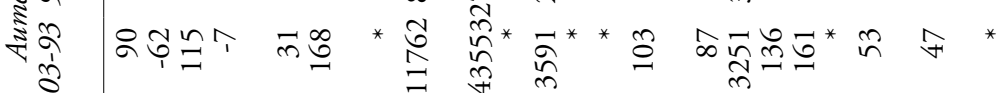

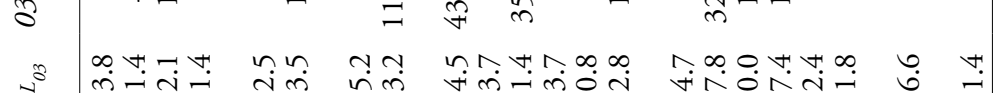

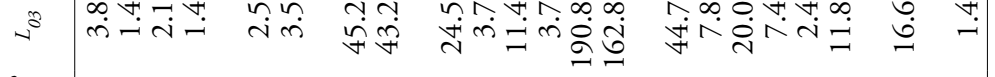

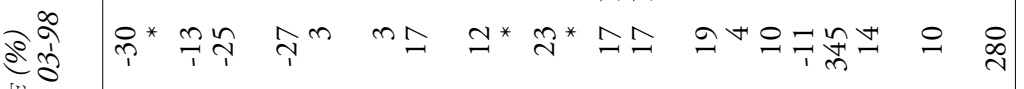

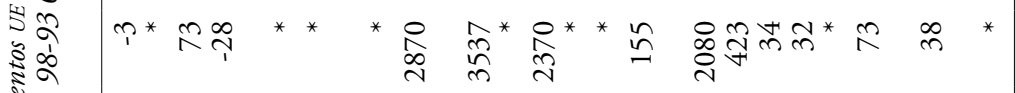

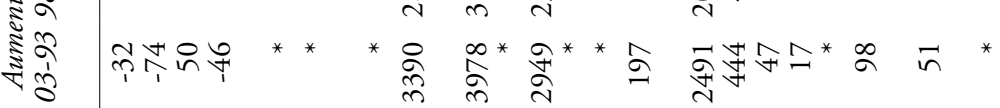

桨

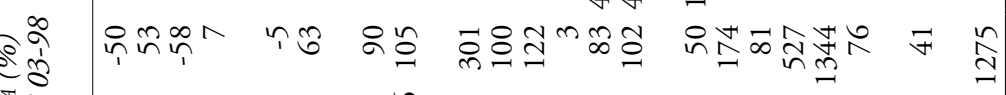

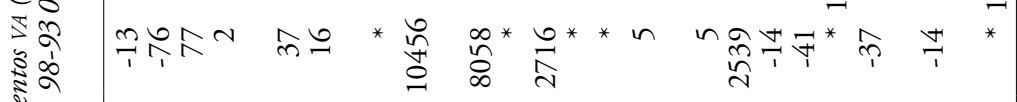

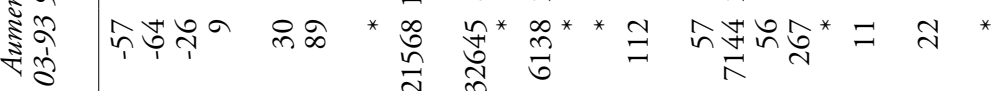

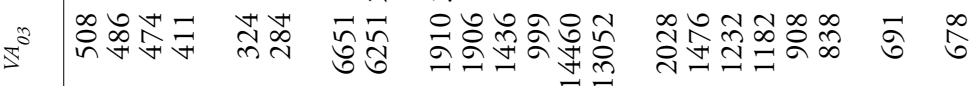

इอ

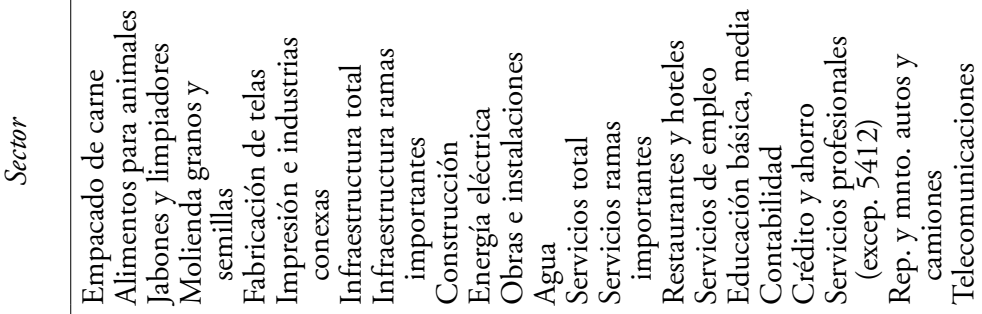

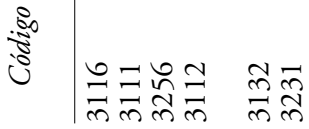

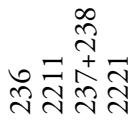

犬ิ 


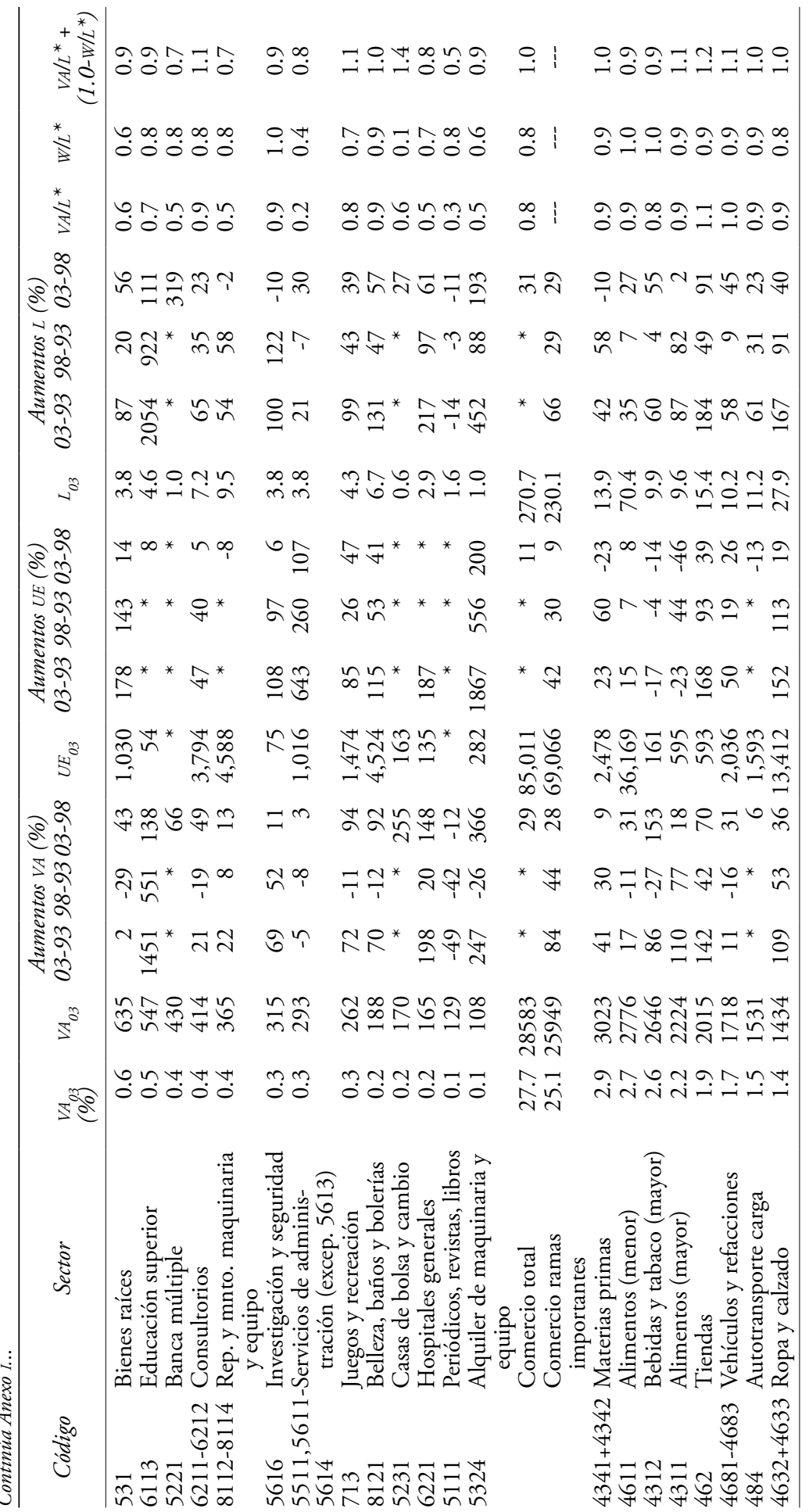




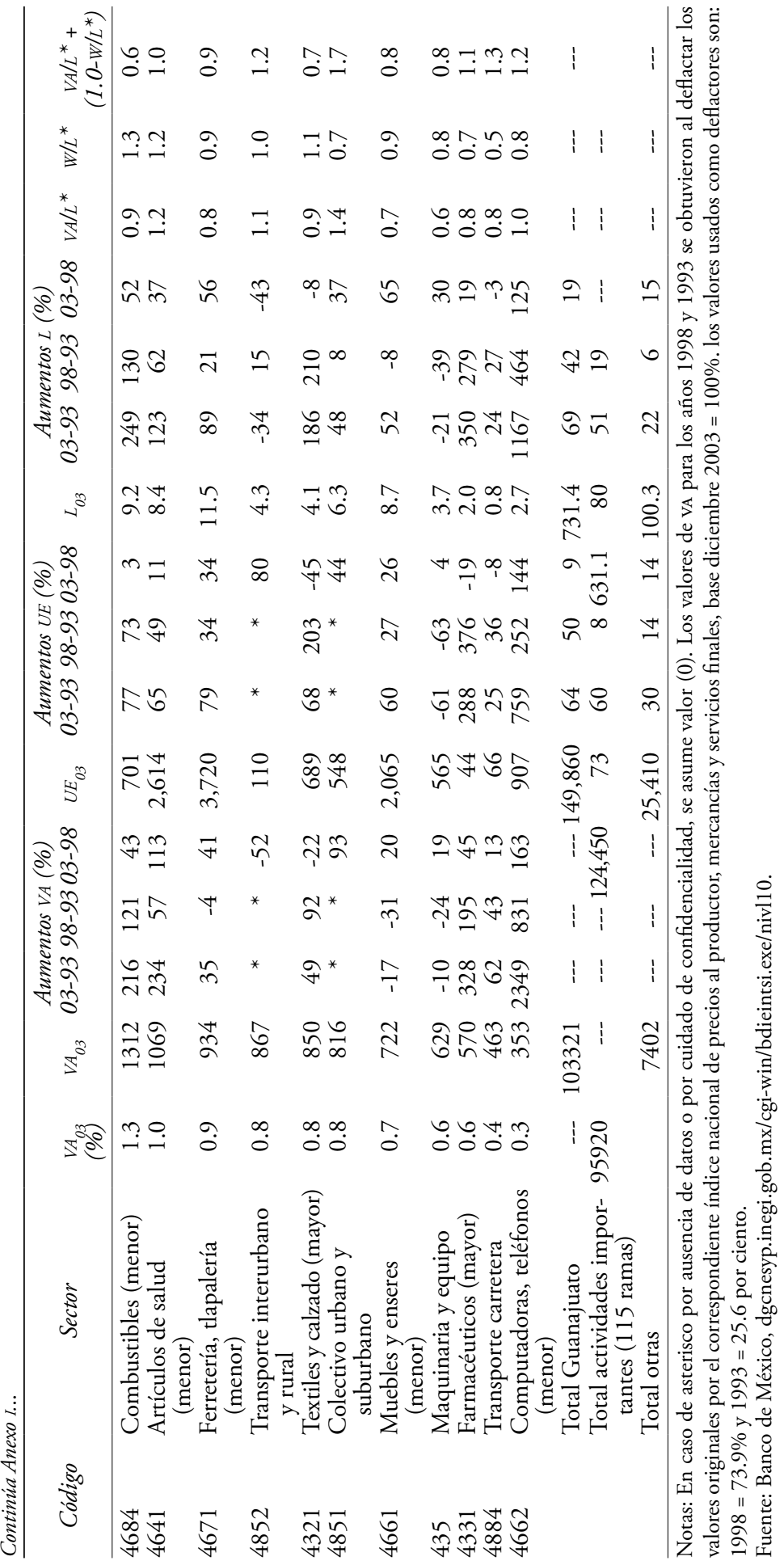




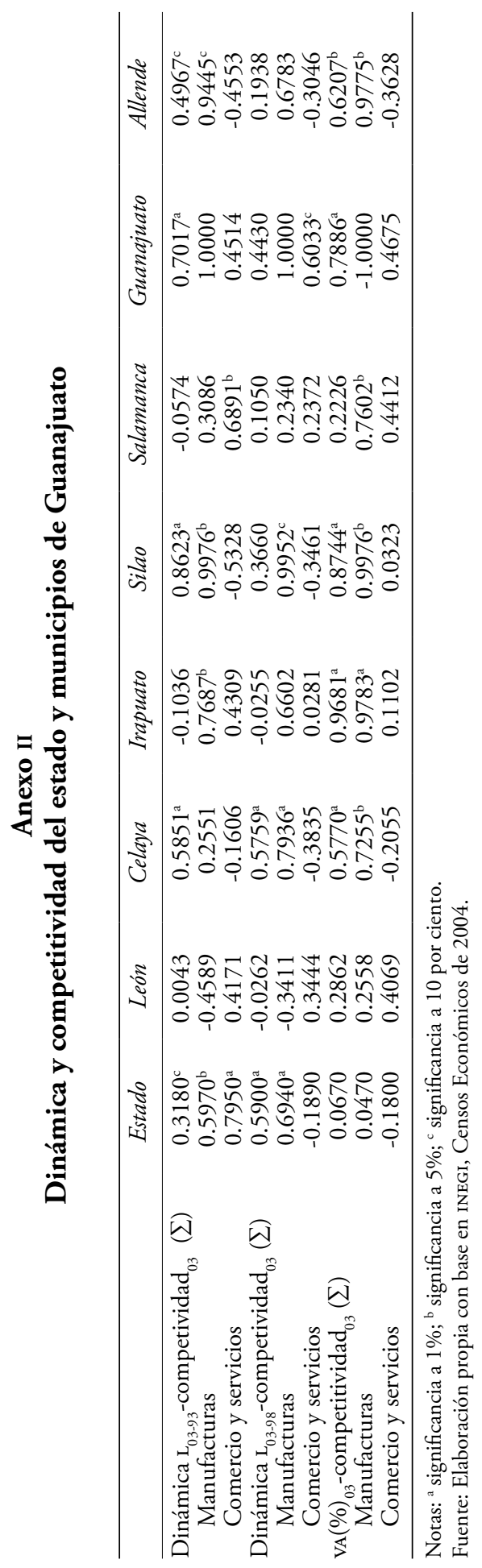




\section{Bibliografía}

Abdel, Guillermo (2000), "Regional and Local System of Innovation in Aguascalientes", en Mario Cimoli (ed.), Developing Innovation Systems: México in a Global Context, Continuum, Nueva York.

Alba, Francisco (1999), "La cuestión regional y la integración internacional de México: una introducción”, Estudios Sociológicos, xvII (51), México, pp. 611-632.

Balassa, Bela (1965), "Trade liberalisation and revealed comparative advantage", Review of Manchester School Economics and Social Sciences, 33, Manchester, pp. 99-123.

Dutrénit, Gabriela y Mario José Capdevielle (1993), “El perfil tecnológico de la industria mexicana y su dinámica innovativa en la década de los ochenta", El Trimestre Económico, 239, Fondo de Cultura Económica, México, pp. 643-664.

Cermeño, Rodolfo, David Mayer y Ariadna Martínez (2009), “Convergencia, divergencia y estratificación. Estudio comparativo de la dinámica de crecimiento de la manufactura en los municipios mexicanos y los condados estadounidenses", El Trimestre Económico, 76 (2), Fondo de Cultura Económica, México, pp. 349-378.

Cimoli, Mario (2000), "Macroeconomic Setting and Production System", en Mario Cimoli (ed.), Developing Innovation Systems: México in a Global Context, Continuum, Nueva York.

Directorio Empresarial siem (2007), Secretaría de Desarrollo Económico Sustentable, Gobierno del Estado de Guanajuato, <http://sde. guanajuato.gob.mx>, noviembre de 2008 .

Enright, Michael (1997), "Regional Clusters and Firm Strategy", en Alfred D. Chandler et al. (eds.), The Dynamic Firm, Oxford University Press, Oxford.

FCCyт (Foro Consultivo Científico y Tecnológico) (2006), Diagnóstico de la politica cientifica, tecnológica y de fomento a la innovación en México (2000-2006), Consejo Nacional de Ciencia y Tecnología, México. 
Estrada, Salvador (2006), "Diferencias regionales en la conducta tecnológica de las empresas manufactureras mexicanas: el caso de Guanajuato", Economia, Sociedad y Territorio, v (20), El Colegio Mexiquense, Zinacantepec, pp. 821-869.

Glasmeier, Amy (2000), "Economic Geography in Practice: Local Economic Development Policy", presentado en el Seminario Internacional Nafin/unam Aprendiendo de las regiones en el mundo: ¿cómo combatir la desigualdad productiva?, mayo, México.

INEGI (Instituto Nacional de Estadística, Geografía e Informática) (2003), XVI Censos Industriales de 2003, INEGI, Mexico.

Krugman, Paul (1996), Development, Geography and Economic Theory, The MIT Press, Masachusets.

oCDE (Organización para la Cooperación y el Desarrollo Económico) (1998), National Innovation Systems: Analytical Findings, OCDE, París.

ocde (Organización para la Cooperación y el Desarrollo Económico) (2007), Competitive Regional Clusters: National Policy Approaches, OCDE, París.

Pavitt, Keith (1984), "Patterns of Technical Change: Towards a Taxonomy and a Theory", Research Policy, 13 (6), Elsevier, Londres, pp. 343-373.

Porter, Michael (1990), The Competitive Advantage of Nations, MacMillan, Londres.

Rodríguez-Posé, Andrés (2000), "Local Production Systems and Economic Performance in France, Germany, Italy, and the United Kingdom", presentado en el Seminario Internacional Nafin-UNAM Aprendiendo de las regiones en el mundo: ¿cómo combatir la desigualdad productiva?, mayo, México.

Shepherd, William (1999), The Economics of Industrial Organization, Prentice Hall, New Jersey.

Sobrino, Jaime (2005), "Competitividad territorial: ámbitos e indicadores de análisis”, Economia, Sociedad y Territorio, dossier especial, 
La economía mexicana en el umbral del siglo XXI, El Colegio Mexiquense, Zinacantepec, pp. 123-183.

Unger, Kurt y Luz Saldaña (1999), "Industrialización y progreso tecnológico: una comparación entre las regiones de México", Estudios Sociológicos, xviI (51), México, pp. 633-682.

Unger, Kurt (2005), "La evolución de la competitividad mexicana en la globalización”, Documento de Trabajo E-318, Centro de Investigación y Docencia Económicas.

Unger, Kurt (2009), "La evolución de la economía de Guanajuato posterior al TLCAN (1993-2003). Competitividad de los sectores y vocaciones de especialización municipales", reporte de resultados principales a Iplaneg y Sefide del Gobierno del Estado de Guanajuato.

Unger, Kurt (2010), Globalización y clusters regionales en México: un enfoque evolutivo, Fondo de Cultura Económica, México.

Recibido: 26 de noviembre de 2009. Reenviado: 29 de julio de 2010. Aceptado: 12 de agosto de 2010.

Kurt Francisco Unger-Rubín. Es doctor en economía por la Universidad de Sussex, Gran Bretańa. Es profesor-investigador en la División de Economía del Centro de Investigación y Docencia Económicas (CIDE). Pertenece al Sistema Nacional de Investigadores (SNI), nivel III. Sus líneas de investigación son: organización industrial aplicada, migración, economía regional, tecnología y competitividad internacional. Entre sus publicaciones recientes destacan: Organización industrial evolutiva, globalización $y$ clusters regionales en México, Fondo de Cultura Económica (2010); "Apertura y empleos: la economía de los sectores comerciables y no comerciables de las regiones de México", en Jesus Arroyo y Salvador Berumen (coords.), Migración a Estados Unidos: remesas, autoempleo e informalidad laboral, Universidad de Guadalajara/Secretaría de Gobernación, México, pp. 29-54 (2009); "Competencia, rentabilidad e innovación: estímulos a I\&D en México”, El Trimestre Económico, LxxviII (1), 309, Fondo de Cultura Económica, México, pp. 1-37 (2010). 